NBER WORKING PAPER SERIES

\title{
BREADTH VS. DEPTH: \\ THE TIMING OF SPECIALIZATION IN HIGHER EDUCATION
}

\author{
Ofer Malamud \\ Working Paper 15943 \\ http://www.nber.org/papers/w15943
NATIONAL BUREAU OF ECONOMIC RESEARCH
1050 Massachusetts Avenue
Cambridge, MA 02138
April 2010

I wish to thank Claudia Goldin, Caroline Hoxby, and Larry Katz for extensive comments, as well as Nittai Bergman, Saar Golde, Jeff Grogger, Michael Kremer, Seema Jayachandran, Bob Lalonde, Steve Machin, Klaus Miescke, Derek Neal, Steve Pischke, Cristian Pop-Eleches, Sarah Reber, Bruce Sacerdote, Anna Vignoles, Abigail Waggoner, Tara Watson and seminar participants at Clemson University, Hebrew University, Harvard University, Michigan State University, Tel-Aviv University, UCSD, UC Riverside, University of Chicago, and the NBER Higher Education meeting for many helpful suggestions. I am grateful to the Universities Statistical Record, the UK Data Archive, and several university administrators in Scotland and England for assistance. All errors are my own. This work was supported by a grant from the Spencer Foundation. The views expressed herein are those of the author and do not necessarily reflect the views of the National Bureau of Economic Research.

NBER working papers are circulated for discussion and comment purposes. They have not been peerreviewed or been subject to the review by the NBER Board of Directors that accompanies official NBER publications.

(C) 2010 by Ofer Malamud. All rights reserved. Short sections of text, not to exceed two paragraphs, may be quoted without explicit permission provided that full credit, including $\odot$ notice, is given to the source. 
Breadth vs. Depth: The Timing of Specialization in Higher Education

Ofer Malamud

NBER Working Paper No. 15943

April 2010

JEL No. I21,J24

\begin{abstract}
$\underline{\text { ABSTRACT }}$
This paper examines the tradeoff between early and late specialization in the context of higher education. While some educational systems require students to specialize early by choosing a major field of study prior to entering university, others allow students to postpone this choice. I develop a model in which individuals, by taking courses in different fields of study, accumulate field-specific skills and receive noisy signals of match quality in these fields. With later specialization, students have more time to learn about match quality in each field but less time to acquire specific skills once a field is chosen. I derive comparative static predictions between educational regimes with early and late specialization, and examine these predictions across British systems of higher education. Using survey data on 1980 university graduates, I find strong evidence in support of the prediction that individuals who switch to unrelated occupations initially earn lower wages but less evidence that the cost of switching differs between England and Scotland. Although more switching occurs in England where students specialize early, higher wage growth among those who switch eliminates the wage difference after several years.
\end{abstract}

Ofer Malamud

Harris School of Public Policy Studies

University of Chicago

1155 East 60th Street

Chicago, IL 60637

and NBER

malamud@uchicago.edu 


\section{Introduction}

Division of labor - the tendency of individuals to specialize in specific occupations - is an important feature of the modern labor market. However, for many professional occupations, such as those held by scientists, engineers, managers, lawyers, and teachers, specialization begins prior to labor market entry when an individual chooses a field of study in university. ${ }^{1}$ The timing of such academic specialization varies across different systems of higher education. In some systems, students are required to choose a field of study before they apply to college. In others, students may postpone the decision until late in their college careers. These differences highlight the trade-off between accumulating more human capital in a particular field by specializing early versus gathering additional information about alternative fields by specializing later. I explore the consequences of early and late specialization by comparing labor market outcomes across two educational systems with different exogenous constraints on the timing of academic specialization. ${ }^{2}$

I introduce a simple model to characterize the timing of specialization across different systems of higher education. I assume that individuals initially take courses in a number of different fields of study but must specialize at some point by choosing one field and taking their remaining courses in this field exclusively. A key aspect of the model is that individuals learn about their unobserved match quality in different fields by taking courses. Each course in a given field of study provides field-specific skills as well as a signal of match quality in that field. Later specialization provides students with more time to learn about match quality in different fields but it affords less time to acquire field-specific skills after a field is chosen. Assuming that wages are increasing in both field-specific skills and match quality, I show that later specialization is preferred when the return to match quality is high relative to the return to specific skills. Extending the model to allow for switching to occupations which are unrelated to the chosen field of study, I predict that individuals who switch fields will earn lower wages than those who enter related fields. This is because switching is associated with a loss in specific skills and because match quality conditional on switching is, on average, lower. Moreover, since switching allows individuals to correct for poor choices made at the point of specialization, this option should be more valuable in regimes where individuals are required to specialize early. Consequently, the difference in expected wages between the early and

\footnotetext{
${ }^{1}$ In a survey of college students in the Boston area, Freeman (1971) finds that most final career plans are made during the college period, and that the choice of a college major and the choice of occupation are closely related.

${ }^{2}$ In a related paper, Malamud (2009), I exploit this exogenous difference in the timing of specialization to test whether higher education provides students with information about their tastes and talents for different fields.
} 
late regime should diminish when switching is possible and the return to match quality is relatively high.

I proceed to examine the labor market consequences of specializing early versus late by comparing across the English and Scottish undergraduate0 systems. In England, students apply to a specific field of study at a particular university while still in secondary school. Once admitted to study a certain field, they usually follow a narrow curriculum that focuses on the chosen subject and allows for few courses in other fields. That is, English students are required to specialize early. In contrast, Scottish students are typically admitted to a broad faculty rather than a specific field. They are required to take several different subjects during their first two years before specializing in a particular field. That is, Scottish students are required to generalize early and specialize late. These differences in the timing of academic specialization between England and Scotland have existed for more than a century. ${ }^{3}$ Since the labor markets in England and Scotland are relatively well integrated and macroeconomic policies are determined by a common government, Britain is a particularly useful setting in which to examine the consequences of early and late specialization.

Using survey data on 1980 university graduates from England and Scotland, I find strong evidence that individuals who switch to unrelated occupations earn lower initial wages. This confirms one of the main predictions of the model. ${ }^{4}$ Although imprecise, estimates of wage differentials between switchers and non-switchers suggest that the cost of switching may be higher in England than in Scotland. Furthermore, since the likelihood of switching fields is substantially higher in England than in Scotland, the model suggests that students in England make more mistakes in choosing their field of study and suffer a corresponding loss in specific skills when trying to correct it. Nevertheless, individuals who switch also experience greater wage growth so that most of the wage differential becomes insignificant after 6 years in the labor market. Finally, controlling for demographic and occupational characteristics, there is no significant difference in average wages and reported subjective satisfaction between individuals in England and Scotland. These findings suggest that, while later specialization is beneficial during the initial years in the labor market, wage differences between regimes with early and late specialization do not persist in later years.

The concept of academic specialization is closely related to the important distinction between

\footnotetext{
${ }^{3}$ More recently, many English institutions have begun to introduce course structures that include more breadth and offer greater flexibility. This might suggest a growing perception that specializing too early may have some drawbacks.

${ }^{4}$ This is consistent with evidence from the literature on "job mismatch" showing that individuals who are overeducated relative to their occupations or under-educated relative to their coworkers earn lower wages. See Sicherman (1991) and Cohn and Kahn (1995) for the US; Dolton and Vignoles (2000) and McMillen et. al. (2007) for the UK.
} 
general and specific education. In changing environments, general education may be more valuable than specific training. ${ }^{5}$ Moreover, general skills are often deemed more useful in implementing new technologies. (Nelson and Phelps, 1966; Welch, 1970) ${ }^{6}$ In the context of academic specialization, individuals who emerge from an educational system which requires early specialization will have more specific skills in a particular field, while their counterparts in a system that allows for later specialization will have more skills in a range of fields. ${ }^{7}$ Thus, according to the model I present in this paper, regimes which allow for later specialization would, all things equal, be preferred when there is substantial labor market volatility. However, with imperfect information about match quality, I derive non-trivial predictions across different educational systems even in the absence of any labor market volatility.

In a static labor market with perfect information, Weiss (1971) shows that it is not optimal to delay the investment in education or change occupations when human capital accumulation is perfectly specific to a particular occupation. Allowing for imperfect information about match quality, I find that it may be better to delay specialization. ${ }^{8}$ Furthermore, the arrival of new information about match quality may lead some individuals to switch to an occupation that is unrelated to their chosen field of study. Note that, in this model, the process of learning about match quality in a particular field is complementary to the acquisition of specific skills in that field. Thus, in contrast to the competing tasks of on-the-job search and firm specific human capital acquisition in Jovanovic (1979b), the trade-off associated with academic specialization arises not between the accumulation of human capital and learning about match quality per se, but rather, between the accumulation of human capital in a particular field and the possibility of learning about match quality in alternative fields.

The paper proceeds as follows: Section 2 develops a simple model of academic specialization and derives comparative static predictions across regimes with early and late academic specialization. Section 3 extends the model to allow for switching to occupational fields which are unrelated to

\footnotetext{
${ }^{5}$ Goldin (2001) suggests that high geographical and occupational mobility may explain the prominence of general education in America, in contrast to the European tradition of vocational and apprenticeship training.

${ }^{6}$ Krueger and Kumar (2004a, 2004b) also argue that the specialized training favored in Europe may account for the slowdown in European economic growth during periods of rapid technological change.

${ }^{7}$ Incorporating a notion of general skills by allowing labor market returns to depend on average skills across fields would make later specialization relatively more attractive. Allowing for spillovers in skills across fields would also tend to make later specialization more appealing because additional learning about match quality would be less costly in terms of forgone skill acquisition.

${ }^{8}$ Altonji (1993) also develops a model where individuals learn their preference between two fields of study by attending college and Arcidiacono (2004) estimates a structural model of student learning, but neither considers the role of academic specialization.
} 
fields of study. Section 4 explores the differences between the English and Scottish systems of higher education in more detail. Section 5 describes the data and the empirical methodology. Section 6 presents results from the regression analysis. Section 7 concludes.

\section{A Simple Model of Academic Specialization}

\subsection{Setup}

Suppose individuals take $n$ courses in each of $k$ fields of study prior to specialization. Each course in a given field provides field-specific skill and a noisy signal of match quality in that field. ${ }^{9}$ In specializing, individuals choose a field and take $(N-n k)$ additional courses in this chosen field of study. After completing a total of $N$ courses, individuals enter an occupation in their chosen field of specialization. Assume that individuals are risk neutral and have identical prior distributions on match quality for each field. Specifically, assume that match quality, $\theta_{i}$, in each field $i$ is a random draw from a normal distribution with the same mean and variance, so that $\theta_{i} \sim N\left(\mu, \sigma_{0}^{2}\right)$. Match quality is therefore uncorrelated across fields. Match quality can include any field-specific component of education that affects wages - for example, inherent ability or interest which contributes to productivity in a specific field. ${ }^{10}$ Allowing for prior means and variances to differ across fields is straightforward and does not alter the main results from the model so long as we abstract from the possibility of switching fields later on.

By taking courses in a given field, individuals will (i) accumulate field-specific skills and (ii) receive noisy signals of their match quality in that field. For simplicity, suppose that the quantity of skills accumulated in a field, $s_{i}$, is equivalent to the number of courses spent studying that field. Each course of study $j$ in field $i$ provides a signal of match quality in that field, $x_{i j}=\theta_{i}+\varepsilon_{i j}$ where $\varepsilon_{i j} \sim N\left(0, \sigma^{2}\right)$ and $j=1, \ldots, n$. Noise in the signal may be due to any number of idiosyncratic factors such as the quality of instruction or the particular circumstances of the student at the time. I assume that skills are perfectly specific to a particular field. Allowing for spillovers across fields would serve to dampen the tradeoff between match quality and skills since additional learning about match quality would be less costly in terms of forgone skill acquisition.

The wage in field $i$ upon entering the labor market is an increasing function of both match

\footnotetext{
${ }^{9}$ McCall (1990), Neal (1999), and Shaw (1987) extend the notion of job match quality presented by Johnson (1978) and Jovanovic (1979a) to the occupational level and present evidence for learning about occupational match quality.

${ }^{10}$ In principle, we can broaden the definition of match quality to include any field-specific component that affects utility (though we only have information on wages and crude measures of satisfaction in our data).
} 
quality and skills: $w_{i}=w\left(\theta_{i}, s_{i}\right)$ so that $\frac{\partial f}{\partial \theta}>0$ and $\frac{\partial f}{\partial s}>0$. For simplicity, I assume that wages are a linear function of match quality and skills, $w\left(\theta_{i}, s_{i}\right)=\alpha \theta_{i}+\beta s_{i}$. I take $\left(\frac{\alpha}{\beta}\right)$ as an indication of the return to match quality relative to the return to specific skills. More generally, we might expect a different functional form for wages across different fields. ${ }^{11}$ In the empirical analysis, I compare outcomes for individuals controlling for field of study to account for mean differences in wages across fields. Finally, for the purposes of the empirical analysis, I suppose that individuals only consider wages when making educational and occupational decisions. However, if instead, I were to consider utility as a function of both wages and non-pecuniary factors as well, I would derive analogous predictions for utility.

\subsection{Choice of field at specialization}

The posterior distribution of match quality after studying $n$ courses in field $i$ is a normal distribution with mean $\mu_{i}^{\prime}$ and variance $\sigma^{\prime}{ }^{12}$ And the quantity of skills in each field at the point of specialization is $s^{\prime}=n$. Therefore, in specializing, risk neutral individuals with identical prior distributions across fields will choose the field of study with the highest expected wages (based on their beliefs $\mu_{i}^{\prime}$ ):

$$
\text { choose } i^{*}=\arg \max _{i=1, \ldots k}\left\{E\left[w\left(\mu_{i}^{\prime}, s^{\prime}\right)\right]\right\}
$$

Since the quantity of specific skills in each field is identical, individuals simply choose the field with the highest posterior mean of match quality, $i^{*}=\arg \max _{i=1, \ldots k}\left\{\mu_{i}^{\prime}\right\} .{ }^{13}$ Thus, the posterior mean of match quality in the chosen field at the time of specialization will be $\mu_{i^{*}}^{\prime}{ }^{14}$ Introducing risk aversion does not alter the decision at the point of specialization if the variances of the prior distributions across fields are identical; individuals would continue to choose the field with the highest posterior mean. However, if more precise information is available about certain fields at the point of specialization (i.e. $\sigma_{0}^{2}$ varies by field), risk averse individuals could decide to choose such fields even when they are associated with lower posterior means.

\footnotetext{
${ }^{11}$ Berger (1988), Grogger and Eide (1995), Hamermesh and Donald (2006), and Rumberger and Thomas (1993), provide evidence that earnings differ by undergraduate major.

${ }^{12}$ The posterior mean is a weighted average of the prior mean and the mean of the signals: $\mu_{i}^{\prime}=$ $\left(\mu \sigma_{0}^{-2}+\sigma^{-2} n \bar{x}_{i}\right) /\left(\sigma_{0}^{-2}+n \sigma^{-2}\right)$ where $\bar{x}_{i}=\frac{1}{n} \sum^{j} x_{i j}$. The posterior variance is $\sigma^{\prime}=\left(\sigma_{0}^{-2}+n \sigma^{-2}\right)^{-1}$. See DeGroot (1970) for a detailed exposition.

${ }^{13}$ Strictly speaking, expected future wages should include expected skills rather than the quantity of skills at the point of specialization. But since expected match quality and skills are separable and individuals are risk neutral, this will lead to the same choice at the point of specialization

${ }^{14}$ Specifically, $\mu_{i^{*}}^{\prime}=\left(\mu \sigma_{0}^{-2}+\sigma^{-2} n \max _{i} \bar{x}_{i}\right) /\left(\sigma_{0}^{-2}+n \sigma^{-2}\right)$.
} 


\subsection{Optimal timing of specialization}

Individuals who specialize later have less time to accumulate specific skills in their chosen field of study but receive more signals in each field prior to specialization. They will therefore have more accurate assessments of their match quality in each field and be less likely to make a mistake in choosing a field. Thus, the optimal point of specialization depends on the return to match quality relative to the return to specific skills:

Proposition 1 The optimal number of courses prior to specialization, $n$, is increasing in $\alpha / \beta$.

See the Mathematical Appendix for a formal proof. Now consider regimes with early and late specialization: An early regime requires individuals to specialize after taking $n^{E}$ courses in each field; a late regime requires individuals to specialize after taking $n^{L}$ courses in each field, where $n^{E}<n^{L}$. I now consider predictions on wages in a baseline case where no field switching is permitted; that is, individuals must enter their chosen field of study. As before, specific skills will be lower and match quality will, on average, be higher for individuals in the late regime. Hence, whether individuals in the early regime ultimately earn higher expected wages than their counterparts in the late regime will depend on the return to match quality relative to the return to field-specific skills.

Corollary 1 A regime with late specialization, $n^{L}$, will have higher wages than a regime with early specialization, $n^{E}$, if the return to match quality is sufficiently higher than the return to specific skills:

$$
E\left[w^{L}\left(\theta_{i^{*}}, s\right)\right]>E\left[w^{E}\left(\theta_{i^{*}}, s\right)\right] \Longleftrightarrow \frac{\alpha}{\beta}>\Omega>0
$$

The Mathematical Appendix provides a proof. Simulations of expected wages also show the behavior of wages over a broad set of parameter values. ${ }^{15}$ Figure 1 plots expected wages for an early and a late regime over the full range of relative returns to match quality which are normalized by taking $\beta=(1-\alpha)$ so that $(\alpha / \beta)$ goes from 0 to $\infty$ as $\alpha$ goes from 0 to 1 . When the relative return to match quality is high, individuals who specialize later will earn higher wages.

\footnotetext{
${ }^{15}$ All simulations are based on 5000 repetitions for $k=2, N=21, \mu_{1}=\mu_{2}=0, \sigma^{2}=100$, and $\sigma_{0}^{2}=25$. Early regimes are characterized by $n^{E}=2$; late regimes are characterized by $n^{L}=6$. Expected wages are determined according to $E\left(w_{i}\right)=E\left(\alpha \theta_{i}+\beta \widehat{s_{i}}\right)$ where $\widehat{s i}=\frac{s_{i}}{N / k}+\mu$ are normalized skills.
} 


\section{Academic Specialization with Field Switching}

\subsection{Decision on whether to switch}

Now suppose that individuals can switch to an occupational field which is unrelated to their field of study prior to entering the labor market. Following specialization, individuals take $(N-n k)$ additional courses in the chosen field and receive more signals about match quality in the chosen field, $i^{*}$. The posterior distribution of match quality in the chosen field after $(N-n k)$ additional signals will be updated to a normal distribution with mean $\mu_{i^{*}}^{\prime \prime}$ and variance $\sigma^{\prime \prime}$. Moreover, the quantity of skills in the chosen field prior to entering the labor market is $s^{\prime \prime}=n+(N-n k)$. So now, given the opportunity to switch to another field prior to entering the labor market, individuals will compare expected wages in the chosen field with expected wages in the next best field:

$$
\text { field switch } \Longleftrightarrow E\left[w\left(\mu_{i^{*}}^{\prime \prime}, s^{\prime \prime}\right)\right]<\max _{i \neq i^{*}} E\left[w\left(\mu_{i}^{\prime}, s^{\prime}\right)\right]
$$

Intuitively, individuals will switch if the posterior mean of match quality in the chosen field falls sufficiently far below the posterior mean of another field to overwhelm the loss in specific skills from switching. If individuals decide to switch, they will always choose the field with the second-highest posterior mean since all fields other than the one chosen are associated with the same quantity of specific skills and posterior variance. The decision whether to switch can therefore be framed as a comparison between the first best field, $i^{*}$, and the field that was second best at the time of specialization, $i^{a}$. The field selected after the second stage is denoted $i^{* *}$ where $i^{* *} \in\left\{i^{*}, i^{a}\right\}$.

The probability of switching to an unrelated occupational field depends on the timing of specialization. Whether the probability of switching is higher in a regime with early or late academic specialization depends, in turn, on the return to match quality relative to the return on specific skills. In an early regime, assessments of perceived match quality in the chosen field experience relatively greater updating following specialization so individuals are more likely to realize they made a mistake and hope to correct it by switching. However, individuals in an early regime also lose more specific skills by switching fields. Hence, the probability of switching will be higher in an early regime only when the relative return to match quality is sufficiently high. ${ }^{16}$ Allowing for risk aversion reduces the likelihood of switching because the lower posterior variance of the chosen

\footnotetext{
${ }^{16}$ This result is expressed formally and proved in Malamud (2007), a companion paper which tests whether higher education, in addition to providing specific skills, also provides information about match quality in fields of study.
} 
field may be sufficiently valuable to risk averse individuals so as to prevent switching to a field with a higher posterior mean. Since this trade-off is more extreme in the early regime where there is greater updating, field switching will be reduced more in the early regime than in the late regime due to the presence of risk aversion.

\subsection{Choice of field at specialization}

If the variance of priors on match quality are identical across fields, individuals do not need to consider the possibility of later switching when making their initial choice of field. However, allowing prior variances on match quality to vary by field introduces option value considerations at the time of specialization. Similar to the prediction derived by Miller (1984), individuals would then tend to specialize in riskier fields because they could switch in case of a bad realization. ${ }^{17}$ Moreover, fields with a larger prior variance would have greater option value in the early regime than in a late regime. With more signals following specialization, greater updating in an early regime generates a higher probability that the ultimate posterior mean will surpass that of the chosen field. Hence, individuals in an early regime will be more likely to choose a field with a lower posterior mean at the point of specialization because of the greater option value. Since, on average, such fields have lower expected match quality than those with the highest posterior mean, we expect more field switching in an early regime due to option value considerations. ${ }^{18}$ Finally, note that fields of study are assumed to provide only field-specific skills. Therefore, the model does not necessarily predict that individuals will choose a different set of fields in early and late regimes.

\subsection{Wages}

The quantity of specific skills for individuals who switch to occupations unrelated to their chosen field of study is always lower than for those who enter related occupations. Furthermore, match quality conditional on switching is generally lower since it is chosen fields with lower match quality that ultimately lead to bad signals and cause switching. Thus, on average, individuals who switch will have lower levels of both match quality and specific skills than those who do not switch: ${ }^{19}$

\footnotetext{
${ }^{17}$ Note, Miller (1984) models job matching as a multi-armed bandit process and derives predictions on the optimal order of sampling jobs. The model of academic specialization in this paper is restricted to a two-stage selection procedure but allows for the simultaneous sampling of different fields.

${ }^{18}$ However, this effect may be small because all fields are sampled prior to specialization and the option value needs to be greater than the difference in the posterior means of match quality between the relevant fields. Furthermore, the presence of risk aversion would counteract the benefits of having high variance in the posterior distributions.

${ }^{19}$ Of course, the following proposition describes the relationship in the cross-section and not for countefactual comparison by individuals. Since individuals decide optimally, those who decide to switch do better, in expectation,
} 
Proposition 2 Individuals who switch will have lower wages than those who do not switch:

$$
E\left[w\left(\theta_{i^{*}}, s\right) \mid w\left(\theta_{i^{*}}, s\right)>w\left(\theta_{i^{a}}, s\right)\right]-E\left[w\left(\theta_{i^{a}}, s\right) \mid w\left(\theta_{i^{a}}, s\right)>w\left(\theta_{i^{*}}, s\right)\right]>0
$$

See the Mathematical Appendix for a formal proof. As an extension, suppose that individuals continue to accumulate field-specific skills on the job, either from on-the-job training or through learning by doing. Then, if there are diminishing returns to specific skills, individuals who switch will have higher rates of wage growth since they begin with lower levels of specific skills in their occupational fields.

The possibility of switching implies that some individuals in each regime will end up with lower skills and higher match quality. Indeed, on average, those individuals who switch earn higher wages than they would have earned in the baseline case without switching. However, since more mistakes are made with early specialization, it is more valuable to be able to correct them through switching in the early regime and we expect the difference in expected wages between the early and late regime to be dampened when the return to match quality is relatively high.

Proposition 3 With field switching, a regime with late specialization, $n^{L}$, will have higher wages than a regime with early specialization, $n^{E}$, if the return to match quality is sufficiently higher than the return to specific skills:

$$
E\left[w^{L}\left(\theta_{i^{* *}}, s\right)\right]>E\left[w^{E}\left(\theta_{i^{* *}}, s\right)\right] \Longleftrightarrow \frac{\alpha}{\beta}>\Omega^{\prime}>0
$$

See the Mathematical Appendix for further discussion. Expected wages in an early and a late regime are shown in Figure 2 for different relative returns to match quality. Note that expected wages in the early regime do converge towards expected wages in the late regime as the relative return to match quality rises and more switching takes place. As in the case without switching, this prediction indicates that the superiority of one regime over the other depends critically on the relative returns to match quality and field-specific skills.

\section{Background: Higher Education in Britain}

The British system of higher education provides a particularly appropriate setting in which to examine the predictions of the model. Undergraduate education in England and Scotland, though similar in aim and overall structure, varies widely in the timing of academic specialization. In

than they would have by remaining in their chosen fields. 
England, students apply to a specific field of study at a particular university. ${ }^{20}$ Once admitted to a specific field, English students usually follow a narrow curriculum that focuses on the main field and allows for little exposure to other fields. ${ }^{21}$ Indeed, most universities in England require students who change fields of study to start university anew (though some do allow for limited changes). In contrast, Scottish students are typically admitted to a broad faculty or school rather than a department; in some universities, admission is to the university at large. ${ }^{22}$ Furthermore, they are required to study several different fields during their first two years. As an undergraduate prospectus for the University of Edinburgh explains:

"You would normally take courses in three or more subjects in the first year and, commonly, these are followed by second courses in at least two of the subjects in your second year. This will then give you a choice from two, or even three, subjects to pursue to degree level, and you can delay this decision until quite a late stage...In choosing courses to be taken in the first two years, you can select from a very wide range of courses offered across several faculties."

Similar course structures exist in most Scottish universities. Scottish universities thus allow for substantial choice among fields of study within faculties and, to some degree, across faculties as well. ${ }^{23}$ Moreover, students in Scotland are required to take a broader range of courses and choose a field of study much later than their English counterparts. ${ }^{24}$ The Handbook for Students and their Advisors of 1980-82 explains that "the standard English degree, whether in science, humanities or social sciences, is a single subject honours degree" whereas "universities in Scotland had traditionally offered a wide range of subject options with multi-subject examinations at the end of the first year." (pp. 17-18) This is also supported by empirical evidence provided in later sections that the proportion of individuals who change their field of study between admission and graduation in Scottish universities is substantially higher than in English universities. Given these differences, it is quite natural to regard the English system of higher education as an early regime and the Scottish system of higher education as a late regime.

There is some variation in the average length of the undergraduate degree between England and Scotland. Although there is some heterogeneity among degrees within each nation, most English

\footnotetext{
${ }^{20}$ There are exceptions: for example, students at Cambridge University are accepted to a broad engineering faculty; students at Keele University are first accepted to complete a year of "foundation studies".

${ }^{21}$ Again, there are exceptions: Cambridge's system of Tripos allows some flexibility in making changes to courses of study; the newer universities of Essex, Kent, and Lancaster allow students to study a broader range of subjects.

${ }^{22}$ For example, faculties at the University of Glasgow include Arts, Biomedical and Life Sciences, Education, Engineering, Information and Mathematical Sciences, Law, Business and Social Sciences, Medicine, and Physical Sciences.

${ }^{23}$ Note that changing fields is not always possible. Certain professional faculties, such as medicine and law, are more insular. Engineering is usually a separate faculty but changes from the physical sciences are often permitted.

${ }^{24}$ Numerous scholars of British educational systems have noted that Scottish institutions allow for later specialization than English ones: e.g. Evans (1976), Hunter (1971), Osborne (1967), Squires (1987).
} 
degrees are completed within 3 years whereas most Scottish degrees are completed within 4 years. However, many Scottish students enter university after 6 years of secondary schooling rather than the 7 years customary in England. According to this calculation, English and Scottish students who attain a BA degree receive roughly the same number of years of schooling (and this is confirmed in the data by examining the age of graduation). Loosely speaking, the first year of university in Scotland may be said to correspond to the final year of secondary school in England. But even so, since English students apply to university in the beginning of their final year of secondary school while Scottish students only make their final choice of field at the end of their second year of university, there is substantial difference in the timing of specialization.

The difference between English and Scottish universities arose from their unique respective historical traditions. English universities were largely independent and free to set their curriculum and course structures. The provincial civic universities established later in urban centers did not substantially depart from the traditions of the "ancient" universities. Even with the introduction of broad faculties and additional courses of study, admissions remained at the departmental level. ${ }^{25}$ On the other hand, Scottish universities became regulated under the Universities (Scotland) Act of 1858 that set up an executive commission to draw up uniform conditions for courses of study. The Universities (Scotland) Act of 1889 further increased the choice of subjects available in Scottish universities, reflecting the "traditional Scottish preference for a broad general education." (Hunter, 1971, p. 237) In large part, these two Acts of Scottish Parliament determined the distinctive characteristics of universities in Scotland, including the emphasis on late academic specialization.

In addition to differences in higher education, England and Scotland also differ in their system of secondary school education. In England, students need GCE Advanced-level examinations (Alevels) in 2 or 3 subjects to gain acceptance into university. ${ }^{26}$ In 1989, a new exam, the Advanced Supplementary examination (AS-level) was brought in to broaden the curriculum; it was to be the same standard as an A-level, but half the content. Students were encouraged to substitute two AS-levels for one of their A-levels but most universities did not regard these examinations as commensurate alternatives and it did little to change the character of English secondary school

\footnotetext{
${ }^{25}$ The main exceptions arise in the (Plate Glass) universities established during the 1960s such as the University of Keele which implemented an experimental modular curriculum.

${ }^{26}$ Interestingly, the introduction of A-levels in 1951 to replace the Higher School Certificates was a response to the criticism that these latter qualifications were denying opportunity to pupils with talent in individual subjects who were less successful in others (especially in foreign language requirements). Indeed, the Higher School Certificates had attempted to ensure that pupils followed a sufficiently broad and balanced curriculum by requiring candidates to achieve the minimum standard in a range of subjects for a pass. Dolton and Vignoles (2002) examine the effect of choosing a broader set of courses in secondary school in the United Kingdon.
} 
education. In Scotland, on the other hand, students need SCE Higher Examinations in 5 or 6 subjects to gain acceptance into university. ${ }^{27}$ More recently, Advanced Highers and Higher Still certifications have been introduced to provide the opportunity for further specialization in secondary school. However, universities continue to use Highers as the primary basis for admission and there is little doubt that the Scottish system of secondary education provides a broader curriculum than the English one. Again, the reasons for these differences in secondary school curriculum can be traced to historical antecedents. In effect, specialization trickled down from the universities to secondary schools. Moreover, the early influence of English universities on secondary school leaving exams was far stronger than that of Scottish universities since Scottish secondary school leaving certificates had to be approved by the Scottish Education Department.

\section{$5 \quad$ Data and Empirical Strategy}

\subsection{Data}

Data for the empirical analysis come from the 1980 National Survey of Graduates and Diplomates (NSGD). The NSGD was a national postal survey of some 8,000 graduates undertaken in 1986/7 by the British Department of Employment. It includes a random sample of one in six university graduates and one in four of all leavers from other institutions in 1980 in Great Britain. ${ }^{28}$ The NSGD contains information about their 1980 qualification, their subsequent labor market experience (occupation, industry, and wages for first and current jobs) and further educational pursuits. There is also information about their high school examination results and some questions regarding satisfaction with the 1980 qualification. Although it is not possible to identify specific universities in the NSGD, there is information on whether students took English or Scottish secondary school leaving exams. Indeed, using school leaving exams as a proxy for type of degree serves to reduce the bias associated with non-random migration to university. ${ }^{29}$ Since the NSGD is not representative of the overall population, we might be concerned that the English and Scottish samples of

\footnotetext{
${ }^{27}$ These Scottish qualifications evolved directly from the earlier Leaving and Intermediate Certificates which required proficiency over a group of subjects rather than in single subjects.

${ }^{28}$ I exclude graduates from polytechnics and other institutions from the present analysis. Engineering students in Scottish universities are oversampled in the NSGD. Consequently, it is important to control for fields of study with the NSGD sample.

${ }^{29}$ While there is some choice available with the type of secondary school, through boarding school perhaps, it is undoubtedly much less than in university (the correlation between Scottish residence and attendance in Scottish high school is .96). Furthermore, few secondary schools in Scotland offer English leaving examinations (the correlation between attendance in a Scottish high school and sitting Scottish leaving examinations is .98).
} 
university graduates may not be comparable because of differing participation rates. Using two nationally representative datasets which include all individuals born in Great Britain during one week in 1958 and 1970 (the National Child Development Study and British Cohort Study respectively), I calculated the percentage of individuals that have attained a first degree from university by age 26 . In both of these datasets, the participation rates to university are remarkably similar between England and Scotland: 8\% of the 1958 cohort and 12\% of the 1970 cohort.

Table 1 shows the average characteristics for the sample of English and Scottish students used in the regression analysis. The average age upon completion of the first degree is almost equivalent among English and Scottish students. Although the average age that students begin university is slightly lower in Scotland, the median age of students during their first year in university is 19 for both England and Scotland (not shown). The raw GPA scores shown in Table 1 are converted from letter grades in the A-level and Scottish Higher school leaving examinations. In the regression analysis, these scores are normalized within nation so that coefficients represent the effect of a one standard deviation increase in GPA. The composition of broad fields of study across the two nations is not too dissimilar, especially after accounting for the oversampling of engineering students from Scotland. Nevertheless, relatively more students in Scotland study life sciences, health sciences, and business and relatively fewer study mathematical and social sciences. The majority of students from England and Scotland enter employment in the UK. The lower rate of unemployment among Scottish individuals is a consequence of the oversampling of engineering graduates who are less likely to be unemployed than others. ${ }^{30}$

The model introduces an important distinction between individuals who enter an occupation that is related to their field of study and those who switch to an unrelated occupation. I construct a variable $S W I T C H$ that captures field switching by grouping fields of study and occupations into categories (see the Data Appendix for more details). As shown in Appendix Table 1, I allow for three levels of classification: narrow (42 categories), broad (12 categories), and very broad (6 categories). Individuals are said to switch to an unrelated occupation when the field of study of their degree and their occupational field are in different categories, subject to the level of classification. Therefore, a field switch is defined as 1 if the occupational field is different from the field of study

\footnotetext{
${ }^{30}$ Note, results from the IEA Third International Mathematics and Science Study (TIMSS) in 1994-95 indicate no significant differences between England and Scotland in the mathematics achievement for students in fourth and eighth grade. There are, however, some differences in the science achievement scores. English students in the eight grade appears to do somewhat better than their Scottish counterparts, although there is no significant difference for fourth graders.
} 
at university, and 0 otherwise. Clearly, broader classifications indicate lower rates of field switching since only drastic changes from fields of study to occupational fields will register. However, the rate of field switching is substantially lower in Scotland than in England according to all classifications. For example, in terms of the broad classification, the rate of field switching in Scotland is between 10 and 20 percentage points lower than the rate of field switching in England. Most of the empirical analysis will focus on the broad classification of fields. ${ }^{31}$

\subsection{Empirical Strategy}

The base sample includes all individuals who attained a BA degree in 1980 and were employed full-time in the first year following completion of their qualification. I exclude individuals pursuing graduate studies while working because this may select for weaker students who need to work while pursuing higher degrees. I explore a variety of alternative sampling restrictions: (i) including graduate students who have occupation data, (ii) including unclassified occupations such as manual and clerical occupations instead of coding them as switches since individuals in one nation may be more likely to end up in non-professional occupations, (iii) coding individuals who end up unemployed as switches since this may be the result of a differential macroeconomic shock across the two nations, and (iv) excluding the fields of education and business or coding individuals who study them as non-switches since they are particularly subject to misclassification (and similarly with combined fields). Finally, I check that the findings hold for students with top high school grades who are clearly free to choose their fields, unconstrained by admissions requirements and the availability of slots.

The theoretical predictions derived regarding wages are examined through the following regression model:

$$
\ln w_{i j}=\beta^{\prime} \mathbf{X}_{i j}+\lambda S C O T_{i j}+\gamma S W I T C H_{i j}+\delta\left(S C O T_{i j} \times S W I T C H_{i j}\right)+\phi_{j}+\varepsilon_{i j}
$$

where $\ln w_{i j}$ is $\log$ annual earnings for individual $i$ in field $j, S C O T_{i j}$ is a dummy variable indicating the individual received a Scottish degree and therefore specialized late, $S W I T C H_{i j}$ is a dummy variable for a field switch, $\phi_{j}$ is a set of field of study effects, $\mathbf{X}_{i j}$ are demographic characteristics, and $\varepsilon_{i j}$ is a disturbance term. The primary demographic controls include sex, age, marital status, high

\footnotetext{
${ }^{31}$ These include: Math/Computer Sciences, Physical Sciences, Architecture, Engineering, Biological Sciences, Health, Social Services, Social Sciences, Business, Law, Education, and Arts.
} 
school GPA, parental socioeconomic status, as well as controls for region of work and industry. Since the log function is a positive monotonic transformation, all of the predictions derived in Section 3 on wages will also hold for log wages. $\lambda$ captures the difference in wages between England and Scotland among individuals that do not experience field switching. $\gamma$ captures the differential in wages in England between individuals who switch and those who do not switch. Finally, $\delta$ captures the difference between Scotland and England in the differential associated with switching. Other parameters of interest include the wage differential from switching for individuals in Scotland $(\gamma+\delta)$ and the wage difference between English and Scottish individuals who switch $(\lambda+\delta)$. All wage regressions use the type of high school leaving examinations as a proxy for the type of degree.

Although I am primarily interested in estimating wage regressions, I also consider the effect of a Scottish degree on the probability of switching:

$$
S W I T C H_{i j}=\theta^{\prime} \mathbf{X}_{i j}+\mu S C O T_{i j}+\phi_{j}+\epsilon_{i j}
$$

where $S W I T C H_{i j}$ and $S C O T_{i j}$ are as defined in equation 1. The set of controls, $\mathbf{X}_{i j}$, includes sex, age, marital status, high school GPA, and parental socioeconomic status. Some specifications also include field of study effects and controls for region of work. In this regression, $\lambda$ captures the difference between England and Scotland in the likelihood of switching. Again, I use the type of school leaving examinations (whether Scottish or English) to estimate a reduced form equation of the probability of field switching.

\section{Results}

\subsection{Wages}

Wage regressions are presented in Table 2. Columns (1), (2) and (3) explore the effects on wages in the first job held in the first year after completing a BA degree, while columns (4), (5), and (6) examine the effects on wages in the job held six years after completing a BA degree. In addition to gender, marital status, age, high school GPA, all wage regressions include controls for field of study, industry, and region of work since wages may differ markedly across fields, regions, and industry for other reasons. Column (1) reveals that there is no significant difference in average annual earnings between England and Scotland in the first year following completion of the degree - the coefficient on $S C O T$ from equation (1) is not statistically significant. But column (2) provides strong evidence 
in support of the theoretical prediction that individuals who switch to an occupation unrelated to their field of study at university earn lower wages in the first year (1981) - the coefficient on SWITCH is negative and significant. Indeed, field switching is associated with a substantial wage loss of around 7 percentage points, comparable in magnitude to the negative wage differential for women in this sample. ${ }^{32}$ The magnitude of the coefficient on SCOT $\times S W I T C H$ in column (3) suggests that the differential associated with field switching is larger in England than Scotland but the estimate is rather imprecise.

Column (4) shows that there is no significant difference in average annual earnings between England and Scotland after six years in 1986/87. Interestingly, columns (5) and (6) indicate that individuals who switched to an occupation unrelated to their field of study at university in the first year earn average annual wages six years later that are no different than their counterparts who did not switch. In other words, controlling for background variables, individuals who experience field switching appear to make up the difference over time. Figure 3 plots log wages in 1981 and 1986/87 predicted on the basis of observable characteristics from the wage regressions of Table 2; specifically, columns (3) and (6). Although insignificant, the differential in initial wages between those who switch and those who do not switch does appear to be larger in England than in Scotland. Robustness checks for all these findings are presented in columns (2), (3), and (4) of Appendix Table 2.

Part of the wage loss among individuals who switch to unrelated occupations may be associated with unobservables which are correlated with field switching rather than a direct causal effect. However, it is important to distinguish between two types of unobserved variables. Although we try to control for ability using high school achievement and success in university, individuals may have additional unobservable traits that affect wages. For example, individuals who are particularly indecisive and therefore switch fields, as suggested in the previous section, may have ended up earning lower wages in any case. ${ }^{33}$ In the model of academic specialization presented earlier, switching fields is endogenous yet individuals switch fields because they receive new information on match quality and not because of some unobserved characteristics. Shocks to information on match quality will generally be unobservable. ${ }^{34}$ But these reflect the inherent uncertainty in the

\footnotetext{
${ }^{32}$ Using this same data, Dolton and Vignoles (2000) find that UK graduates who are overeducated relative to their reported job requirements earn singificantly lower wages than their peers.

${ }^{33}$ While I don't find that the coefficient on $S W I T C H$ is affected when controlling for whether individuals changed fields of study during university, it may still capture some unobservable traits that differ across individuals.

${ }^{34}$ College grades may serve as a useful proxy for these unobservable shocks. However, this is not available in this
} 
process of learning about match quality rather than an innate trait. The fact that individuals who switch tend to catch up with their counterparts who did not switch suggests that this may be the more important explanation for the initial wage loss associated with switching.

That individuals who experience field switching make up the difference in wages over time is interesting but not necessarily surprising. Recall that predictions on wage growth depended on additional assumptions. If field-specific skills are also accumulated on the job but these skills have diminishing returns, we would expect that field switching is associated with greater wage growth in the early years after graduation. Table 4 shows the growth in annual wages over the six years following completion of a BA degree. With coefficients on SWITCH that are almost significant, columns (2) and (3) suggest that individuals who switch to an unrelated occupation upon entering the labor market experience greater wage growth than their counterparts who do not switch. Moreover, although insignificant, the signs on SCOT and SCOT * SWITCH accord with the general intuition: individuals who switch in Scotland experience lower wage growth than their English counterparts since they have higher levels of specific skills upon entering the labor market; individuals who do not switch in Scotland experience greater wage growth than their English counterparts since they have lower levels of specific skills upon entering the labor market.

\subsection{Field Switching}

Table 3 examines field switching between England and Scotland. We estimate a reduced-form equation where $S C O T$ is a dummy variable identifying whether students took English or Scottish secondary school leaving exams. All regressions include controls for gender, marital status, age, SES level, and high school GPA. In column (1), I estimate the difference in the probability of field switching between England and Scotland without controlling for fields of study or region of work. Similar to the raw difference shown in Table 1, the estimated difference in field switching is approximately 15 percentage points, which is substantial given that the rate of field switching in Scotland is about .34. Once I control for the composition of fields across nations in column (2), the estimated differential in field switching declines substantially. In other words, not only do individuals in Scotland switch less, but they also tend to study fields that are associated with less switching. ${ }^{35}$ In column (3), I add controls for region of work and the coefficient on SCOT becomes

\footnotetext{
context because students in Britain do not take modular courses, each with a separate grade.

${ }^{35}$ While it is possible that English students wish to choose fields which facilitate switching in order to avoid specializing in an excessively narrow field, the number of slots in each field in England is essentially determined by government funding.
} 
insignificant, suggesting that there may be different preferences for related qualifications among employers in England and Scotland. However, this specification needs to be interpreted with care since the decision to work in England or Scotland is probably endogenous; individuals who decide to switch may also make systematically different decisions about where they wish to work.

The NSGD also contains information on student outcomes six years following the completion of their degree. Columns (4), (5), and (6) indicate that the differential in field switching between England and Scotland remains after six years. Even stronger results are obtained if we consider all individuals employed six years following completion of the BA degree by including those who were not employed in the first year after completing their degree (results not shown). This suggests that individuals in England continue to experiment more than individuals in Scotland once in the labor market. Robustness checks for all these findings are presented in column (4) of Appendix Table 2. Since the likelihood of switching fields is substantially higher in England than in Scotland, the model suggests that more students in England suffer a loss in specific skills when trying to correct mistakes in their initial choice of field. Thus, at least during the initial years of labor market experience, a regime with early specialization appears to be associated with more costly switches than one with later specialization.

\subsection{Other results}

Although outside the scope of the model proper, I also consider several labor market outcomes over time. The preceding section already examined the results on wage growth from Table 4 . Columns (4), (5), and (6) of Table 4 explore occupational mobility which is defined as a further change in occupational field following entry into the labor market. ${ }^{36}$ Individuals who experience field switching are significantly more likely to change to a job in a different occupational field after several years. This is consistent with the theoretical analysis because individuals who switch have the same level of specific skills in alternative fields so that further changes in occupation are not as severely penalized. Again, it is important to keep in mind that some individuals who switch may simply be inherently less stable workers. Furthermore, among individuals who do not switch, those in Scotland are significantly less likely to change to another occupation in later years.

Finally, respondents in the NSGD were asked: "On reflection, how beneficial has your [1980]

\footnotetext{
${ }^{36} \mathrm{On}$ a related note, there appear to be no significant differences in formal job training between England and Scotland. Nonetheless, there may still be greater informal learning on the job for Scottish individuals to make up for lower levels of skill upon entering the labor market.
} 
qualification been to you in:" (i) getting an interesting job; (ii) securing a good income; and (iii) becoming a widely educated person. Based on simple unconditional means, Scottish individuals report higher levels of getting an interesting job than their English counterparts (but these are only marginally significant). Table 5 highlights regression results from these subjective assessments. ${ }^{37}$ Individuals who switch to an occupation unrelated to their field of study are significantly less likely to consider their qualification beneficial in obtaining an interesting job. Indeed, this effect remains strong even after controlling for wages, subjective assessments of securing a good income, and fields of study. It is possible that individuals who switch consider themselves as having interesting jobs but not as a direct result of their qualification. Nevertheless, this provides some suggestive evidence for the non-pecuniary benefits of entering an occupation related to the field of study at university. Individuals who experience field switching are significantly more likely to report that their qualification contributed to their becoming more widely educated. However, this effect becomes insignificant once controls for field of study are included, suggesting that individuals who consider themselves widely educated were the ones that selected certain fields of study with particularly high rates of switching (e.g. humanities and social sciences).

\section{Conclusion}

Specialization is a fundamental feature of many economic decisions. This paper examines the tradeoff between the acquisition of specific skills early in one's college education versus broader training and learning about match quality in different fields of study. I develop a model of specialization in which individuals accumulate field-specific skills and receive noisy signals of match quality by taking courses in different fields of study. I also extend the model to allow for switching to occupations which are unrelated to the chosen field of study upon entry into the labor market. Then I derive and test comparative static predictions between regimes with early and late specialization across the corresponding English and Scottish systems of higher education. I find strong evidence in support of the prediction that individuals who switch to unrelated occupations experience lower initial wages. Though not significant, the sign of the wage differential associated with switching suggests a larger wage penalty in England than Scotland. Moreover, since the probability of switching fields is substantially higher in England than Scotland, more individuals in England suffer a loss

\footnotetext{
${ }^{37}$ These regressions are run as ordered probits. Categories include: "not at all", "a little", "a lot", and "a great deal". Similar results are obtained when collapsing these categories into larger groupings.
} 
in initial wages. Nevertheless, I also find that individuals who switch tend to experience greater wage growth so that wage differences between those who do and do not switch become insignificant after 6 years in the labor market. Furthermore, controlling for demographic and occupational characteristics, there is no significant difference in average wages or reported subjective satisfaction between England and Scotland. Together, these findings suggest that, while early specialization is associated with more costly switches upon entering the labor market, differences in wages across educational systems with early and late specialization do not persist over time.

How should we interpret the absence of significant differences in average earnings between England and Scotland? Based on the model, this result suggests that the benefits to higher match quality from later specialization is roughly in balance with the benefits to more specific skills from early specialization. On the other hand, the pattern of switching indicates that the return to match quality is relatively high as compared with the return to specific skills. There are several ways to reconcile these findings. First, it is possible that the benefits of later specialization are mostly associated with non-pecuniary considerations which are captured by field switching but missed in a measure of wages. Second, as explained in the discussion of Proposition 3 and shown in Figure 2, differences between early and late specialization tend to diminish when switching is possible and the return to match quality is relatively high, because individuals in the early regime are able to correct for their initial mistakes. Finally, there is a range of parameter values for the relative return to match quality where both regimes yield similar returns even though the early regime has a higher rate of switching. ${ }^{38}$ Distinguishing between these alternative explanations is an important area for further research.

Whether one regime is preferred to another also depends on other structural parameters, such as the accuracy of information on match quality prior to commencing education. A lower prior variance on match quality would imply that a shorter period of experimentation is more valuable. Hence, if certain populations have more accurate information about their match quality, a regime with early specialization may not necessarily lead to many costly mistakes. Indeed, with a heterogeneous population, the benefits associated with early or late specialization may accrue to different individuals. The theoretical model abstracts from distributional concerns by assuming that individuals are identical but these considerations may, in fact, be important in evaluating different

\footnotetext{
${ }^{38}$ This can occur when the relative return to match quality at which the probability of switching in the early regime crosses that of the late regime is below the relative return to match quality at which the expected wages in the late regime cross those of the early regime.
} 
systems of higher education. In a broader sense, however, both distributional considerations and possible inefficiencies arise because individuals are forced to specialize at a particular time. Allowing individuals to choose when to specialize should be optimal, especially with a heterogenous population.

The American system of higher education is often cited as an example of an educational system with a broad undergraduate curriculum and relatively late specialization. However, though the U.S. has a strong liberal arts tradition that emphasizes general education and allows for later specialization, American undergraduates can exploit their elective courses and specialize early, if they wish. The U.S. system of higher education is not so much characterized by a broad curriculum and late specialization as by flexibility in breadth and timing of academic specialization. As mentioned above, a system that allows individuals to choose when to specialize should be optimal if students have sufficient information to experiment in a productive fashion. But if there is some lumpiness in human capital investments and students do not have sufficient information to experiment in a productive manner, such flexibility can lead students to end up with unproductive programs of study. Thus, Trow (1999) has argued that American undergraduates often take incoherent courses of study and indulge in excessive experimentation. Examining whether the flexibility of the American educational system can improve on both the English and Scottish systems would be a valuable next step in extending our knowledge of academic specialization. 


\section{References}

Afonja, B. (1972): "The moments of the maximum of correlated normal and t-variates," $J . R$. Statistical Society B, 34, 251-262

Altonji, J.G. (1993): "The Demand for and Return to Education When Education Outcomes Are Uncertain," Journal of Labor Economics 11(1), 48-83

Arcidiacono, P. (2004): "Ability Sorting and the Returns to College Major," Journal of Econometrics, Vol. 121, Nos. 1-2, 343-375

Berger, M.C. (1988): "Predicted Future Earnings and Choice of College Major," Industrial and Labor Relations Review 41(3), 418-29

Betts, J. (1996): "What do Students Know about Wages? Evidence from a Survey of Undergraduates," Journal of Human Resources 31(1), pp. 27-56

Bose, R.C. and S.S. Gupta (1959): "Moments of Order Statistics from a Normal Population," Biometrika 40, 318-335

Bross, I. (1950): "Two choice selection," Journal of the American Statistical Association, 45, $530-540$

Cohn E. and S.P. Kahn (1995): "The wage effects of overschooling revisited," Labour Economics $2(1), 67-76$

DeGroot, M. H. (1970): Optimal Statistical Decisions. McGraw-Hill Company

Department of Employment (1988) National Survey of 1980 Graduates and Diplomates, 19861987 [computer file]. Colchester, Essex: UK Data Archive [distributor], SN: 2314

Dolton, P.J. and A. Vignoles (2000): "The incidence and effects of overeducation in the U.K. graduate labour market" Economics of Education Review 19(2), 179-198

Dolton, P.J. and A. Vignoles (2002): "Is a Broader Curriculum Better?" Economics of Education Review 21, 415-429

Dunnet, C.W. (1960): "On Selecting the Largest of $k$ Normal Population Means," J. R. Statistical Society B, 22, 1-40.

Evans, K. (1975): The Development and Structure of the English Educational System. University of London Press

Freeman, R. (1971): The Market for College Manpower: A study in the economics of career choice. Harvard University Press

Goldin, C. (2001): "The Human-Capital Century and American Leadership: Virtues of the Past," Journal of Economic History 61(2), 263-292

Grogger, J. and E. Eide (1995): "Changes in College Skills and the Rise in the College Wage Premium," Journal of Human Resources 30, 280-310

Grossman, S.J., Kihlstrom, R.E., and L.J. Mirman (1979): "A Baysian Approach to the Production of Information and Learning by Doing," Review of Economic Studies 44, 533-547 
Gupta, S.S. and K.J. Miescke (1996): "Bayesian look ahead one-stage sampling allocations for selection of the best population," Journal of Statistical Planning and Inference 54, 229-244

Gupta, S.S. and K.J. Miescke (1994): "Bayesian look ahead one stage sampling allocations for selecting of largest normal mean," Statistical Papers 35, 169-177

Hamermesh D., and S. Donald (2006): "The Effect of College Curriculum on Earnings: An Affinity Identifier for Non-Ignorable Non-Response Bias," mimeo

Hunter, S.L. (1971): The Scottish Educational System. Oxford: Pergamon Press

Hvide, H.K. (2003): "Education and the Allocation of Talent," Journal of Labor Economics 21(4), 945-976

Johnson, W.R. (1978): “A Theory of Job Shopping," Quarterly Journal of Economics 92(2), $261-278$

Johnson, W.R. (1979): "The Demand for General and Specific Education with Occupational Mobility," Review of Economic Studies 46(4), 695-705

Johnstone, D.B. and P.A. Maloney (1998): "Enhancing the Productivity of Learning: Curricular Implications," Enhancing Productivity: Administrative, Instructions, and Technological Strategies - New Directions for Higher Education (eds. J.E. Groccia and J.E. Miller) Jossey-Bass Publishers.

Jovanovic, B. (1979a): "Job Matching and the Theory of Turnover," Journal of Political Economy $87(5), 972-990$

Jovanovic, B. (1979b): "Firm-specific Capital and Turnover," Journal of Political Economy 87(6), $1246-1260$

Krueger, D. and K. Kumar (2004a) "Skill-Specific rather then General Education: A Reason for US-Europe Growth Differences?" Journal of Economic Growth 9(2): 167-207

Krueger, D. and K. Kumar (2004b) "US-Europe Differences in Technology-Driven Growth: Quantifying the Role of Education" Journal of Monetary Economics 51(1): 161-190

Malamud, O. (2009) "Discovering One's Talent: Learning from Academic Specialization," NBER Working Paper 15522

McCall, B. (1990): "Occupational Matching: A Test of Sorts," Journal of Political Economy 98(1), 45-69

McMillen, D.P., Seaman, P.T., L.D. Singell (2007): "A Mismatch Made in Heaven: A Hedonic Analysis of Overeducation and Undereducation," Southern Economic Journal 73(4): 901-930

Miescke, K.J. (1999): "Bayes sampling designs for selection procedures". Invited chapter in: Multivariate, Design, and Sampling, S. Ghosh ed., M. Dekker, New York, 93-117.

Miller, R. (1984): "Job Matching and Occupational Choice," Journal of Political Economy 92(6), $1086-1120$

Neal, D. (1999): "Complexity of Job Mobility among Young Men," Journal of Labor Economics $17(2), 237-261$ 
Nelson, R.R. and E.S. Phelps (1966): "Investment in Humans, Technological Diffusion, and Economic Growth," American Economic Review, 69-75

Osborne, G.S. (1967): Scottish and English Schools: A comparative survey of the past fifty years. University of Pittsburgh Press

Rumberger, R.W. and S. Thomas (1993) "The Economic Returns to College Major, Quality and Performance: A Multilevel Analysis of Recent Graduates," Economics of Education Review $12(1), 1-19$

Shaw, K.L. (1987): "Occupational Change, Employer Change, and the Transferability of Skills," Southern Economic Journal 53, 702-719

Sicherman N. (1991): "Overeducation in the Labor Market," Journal of Labor Economics 9(2), 101-123

Spence, M. (1973): “Job Market Signaling," Quarterly Journal of Economics 87, 355-374

Squires, G. (1987): "The Curriculum," British Higher Education (ed. Tony Becher). London: Allen \& Unwin

Trow, M. (1999): "From Mass Higher Education to Universal Access: The American Advantage" Minerva 37, 1-26

University of Edinburgh: 2003 Undergraduate Prospectus

Weiss, Y. (1971): "Learning by Doing and Occupational Specialization," Journal of Economic Theory 3, 189-198

Welch, F. (1970): "Education in Production," Journal of Political Economy 78(1), 35-59

Wetherill, G.B. and J.B. Ofosu (1974): "Selection of the Best of k Normal Populations," Applied Statistics 23(3), 253-277 


\section{A Data Appendix}

Complete documentation for the National Survey of 1980 Graduates and Diplomates, 1986-1987 are available from the UK Data Archive: http://www.data-archive.ac.uk. Details of the variables constructed for this study are described as follows:

\section{Field switch}

A field switch is defined as a binary variable that takes on a value of 1 if an individual is employed in an occupation that is unrelated to his major field of study at the undergraduate level, and 0 otherwise. In order to determine whether an individual is employed in an occupation that is related or unrelated to his field of study, I group fields of study and occupations into categories. As shown in Appendix Table 1, I allow for three gradations of classification: narrow (42 categories), broad (12 categories), and very broad (6 categories). Occupations and fields of study are coded according to each of the alternative classifications. Where the occupation and field of study are classified in different categories, the field switch variable takes on a value of 1 . For example, an individual that studies physics at university will have their field of study coded as "physics" according the narrow classification, "physical sciences" according to the broad classification, and "mathematical, computer, and physical sciences" according to the very broad classification. If this individual is employed as a computer programmer, the field switch variable will take on a value of 1 according to the narrow and broad classifications and a value of 0 according to the very broad classification. Combined fields are considered switches if the individual is not employed in any of the fields mentioned. I focus on the broad classification in most of the analysis in this paper. I also consider field switching from the graduate level. This variable is defined analogously except that the field of study is the one studied at the graduate level.

\section{High school GPA}

Scores on secondary school leaving exams are officially coded as letter grades (A, B, C, etc.). These are converted into numerical scores where $\mathrm{A}=10, \mathrm{~B}=8, \mathrm{C}=6, \mathrm{D}=4$, and $\mathrm{E}=2$. Average scores are then standardized by nation and combined so that the overall distribution of high school GPA has mean 0 and standard deviation 1.

\section{SES}

Individual SES scores are based on parental occupations as follows: 0-unstated, retired, or unknown, 1-professionals workers, 2-intermediate workers, 3-skilled non-manual, 4-skilled manual, 5-partially skilled, 6-unskilled, and 7-unemployed.

\section{Region of Work}

Region of work is classified as London, Southern England, Midlands, East Anglia, Northern England, Wales, Scotland, Northern Ireland or abroad.

\section{Industry}

Industry are classified according to broad SIC codes: Agriculture, Forestry, and Fisheries (0), Mining (1), Mineral Extraction and Production (2), Heavy Manufacturing (3), Light Manufacturing (4), Construction (5), Wholesale and Retail Trade (6), Transportation, Communication, and Public Utilities (7), Financial and Business Services (8), Professional and Related Services (9)

\section{Wages}

Wages are annual earnings as reported by individuals in a retrospective survey. Accurate measures of wages are available at two times: starting wages in the first job and "current wages" in the last job reported approximately 6 years after completing the first degree. 


\section{B Mathematical Appendix}

The mathematical appendix provides a formal treatment of the model of academic specialization presented in the main text. For ease of exposition, the structure of the appendix and most of the notation parallels the main text.

\section{Formal Setup}

Suppose $N$ courses are taken in $k \geq 2$ fields of study. Let $F_{1}, \ldots, F_{k}$ be normal populations associated with fields of study $i=1, \ldots, k$, each with unknown mean $\theta_{1}, \ldots, \theta_{k}$ and a common known variance $\sigma^{2}>0$. The unknown means $\theta_{1}, \ldots, \theta_{k}$ represent unobserved match quality in each field.

\section{Sequence of observations}

In Stage 1, $n$ observations from each population $F_{i}$ are observed. These correspond to observations on match quality from courses taken in each field of study prior to specialization. The sample means of these observations, $X_{i}$, are independent and distributed $N\left(\theta_{i}, p^{-1}\right)$ with $p=n \sigma^{-2}$. In Stage 2 , one population, $i^{*}$, is selected for further sampling and $(N-n k)$ additional observations are observed from this population. These correspond to observations on match quality in the chosen field from courses taken following specialization. The sample mean of the second set of observations, $Y$, is distributed $N\left(\theta_{i^{*}}, q^{-1}\right)$ with $q=(N-n k) \sigma^{-2}$ and where $\theta_{i^{*}}$ is the (unknown) mean of the population chosen after Stage $1 .{ }^{39}$

Beliefs on match quality

Belief about match quality $\theta_{1}, \ldots, \theta_{k}$ are represented by the parameters $\widehat{\theta}_{1}, \ldots, \widehat{\theta}_{k}$. These parameters are random and follow independent and identical prior distributions assumed to have $\widehat{\theta}_{i} \sim N\left(\mu, \nu^{-1}\right)$ with $\nu=\sigma_{0}^{-2}$. The conditional distribution of $\widehat{\boldsymbol{\theta}}$ at each stage can be expressed as follows:

$$
\begin{aligned}
& \widehat{\theta}_{i} \quad \mid \quad \mathbf{X}=\mathbf{x} \sim N\left(\frac{p x_{i}+\nu \mu}{p+\nu},(p+\nu)^{-1}\right), \quad i=1, \ldots, k \text { independent } \\
& \widehat{\theta}_{i} \quad \mid \quad \mathbf{X}=\mathbf{x}, Y=y \sim N\left(\frac{\pi \mu_{i}(\mathbf{x})+q_{i} Y}{\pi+q},\left(\pi+q_{i}\right)^{-1}\right), \quad q_{i^{*}}=q \text { and } 0 \text { otherwise }
\end{aligned}
$$

where $\pi=p+\nu$ represents the relative combined (prior plus sampling) information gained from field $F_{i}$, and where $\mu_{i}(\mathbf{x})=\left(p x_{i}+\nu \mu\right) /(p+\nu)$ represents the estimated mean of field $F_{i}$ after Stage 1. In terms of the notation in the main text, $\mu_{i}^{\prime}=\mu_{i}(\mathbf{x})$ and $\mu_{i}^{\prime \prime}=\mu_{i}(\mathbf{x}, y) .^{40}$

\section{Payoffs}

The payoff associated with field $F_{i}$ is denoted by $w_{i}=\alpha \theta_{i}+\beta s_{i}$ where $s_{i}$ is the cumulative number of observations from field $F_{i}$. This payoff represents the wage received in field $i$ upon entering the labor market. In terms of the model of academic specialization, $\alpha$ is the return to match quality and $\beta$ is the return to specific skills. Note that we can express the loss function associated with population $F_{i}$ as $L_{i}(\boldsymbol{\theta}, s)=-\alpha \theta_{i}-\beta s_{i}{ }^{41}$

\section{Decision rules}

\footnotetext{
${ }^{39}$ Since $X_{i}$ and $Y_{i^{*}}$ already correspond to the mean of the samples, we will use $x_{i}$ and $y_{i^{*}}$ instead of $\bar{x}_{i}$ and $\bar{y}_{i^{*}}$.

${ }^{40}$ Note also that the conditional distribution of $Y$ given $\mathbf{X}=\mathbf{x}$ is distributed $N\left(\mu_{i}(\mathbf{x}), w\right)$ with $w=(\pi+q) \pi q$.

${ }^{41}$ This corresponds to a linear loss function, $L_{i}(\boldsymbol{\theta}, s)=\theta_{[k]}-\theta_{i}$, where $\theta_{[k]}=\max \left\{\theta_{1}, \ldots, \theta_{k}\right\}$ is normalized to zero and with an additional negative cost associated with the amount of sampling from the population $i$.
} 
After $\mathbf{X}=\mathbf{x}$ has been observed at Stage 1, the Bayes selection rule $i^{*}=d_{1}^{*}(\mathbf{x})$ can be found by minimizing the posterior expected loss (or in our framework, maximizing posterior expected wages):

$$
\begin{aligned}
E_{X}\left(L\left(\widehat{\boldsymbol{\theta}}, d_{1}^{*}(\mathbf{X})\right) \mid \mathbf{X}=\mathbf{x}\right) & =\max _{i=1, \ldots, k} E_{X}\left(\alpha \widehat{\theta}_{i}+\beta s_{i} \mid \mathbf{X}=\mathbf{x}\right) \\
& =\alpha \max _{i=1, \ldots, k} E_{X}\left(\widehat{\theta}_{i} \mid \mathbf{X}=\mathbf{x}\right)+\beta s \\
& =\alpha \max _{i=1, \ldots, k} \mu_{i}(\mathbf{x})+\beta s=\alpha\left(\frac{p\left(\max _{i=1, \ldots, k} x_{i}\right)+\nu \mu}{p+\nu}\right)+\beta s
\end{aligned}
$$

where $s$ corresponds to the specific skills in each field which are equivalent across fields. The optimal selection, $i^{*}$, at Stage 1 will therefore be the population with the largest observed sample mean after Stage 1 since $d_{1}^{*}(\mathbf{x})=\arg \max _{i=1, \ldots, k} x_{i}$. This is intuitive since, with identical prior distributions on match quality, the only distinguishing feature of each population is the information received in Stage 1. Let $x_{[1]}<x_{[2]}<\cdots<x_{[k]}$ denote the order sample means from Stage 1 and $\mu_{[1]}(\mathbf{x})<\mu_{[2]}(\mathbf{x})<\cdots<\mu_{[k]}(\mathbf{x})$ denote the ordered posterior means from Stage 1. Note that, in terms of the notation in the main text, $\mu_{i^{*}}^{\prime}=\mu_{[k]}(\mathbf{x})$ and $\mu_{i^{a}}^{\prime}=\mu_{[k-1]}(\mathbf{x})$.

Similarly, after $Y=y$ has been observed at Stage 2, the Bayes selection rule $i^{* *}=d_{2}^{*}(\mathbf{x}, y)$ will satisfy

$$
E\left(L\left(\widehat{\boldsymbol{\theta}}, d_{2}^{*}(\mathbf{X}, \mathbf{Y})\right) \mid \mathbf{X}=\mathbf{x}, Y=y\right)=\max _{i=1, \ldots, k} E\left(\alpha \widehat{\theta}_{i}+\beta s_{i} \mid \mathbf{X}=\mathbf{x}, Y=y\right)
$$

These Bayes selection rules yield the maximum posterior expected wages, or Bayes risk, of their respective problems in Stages 1 and 2. Let $\mu_{i^{*}}^{\prime \prime}=\mu_{[k]}(\mathbf{x}, y)$ denote the posterior mean of field, $i^{*}$, after Stage 2. An important feature of this decision problem is that the selection $i^{* *}=d_{2}^{*}(\mathbf{x}, y)$ after Stage 2 may differ from the selection $i^{*}=d_{1}^{*}(\mathbf{x})$ after Stage 1 since further observations in Stage 2 may reveal that the initial choice was not as good as initially thought. This corresponds precisely to the possibility of switching fields expressed in the main theoretical framework.

\section{Proof of Proposition 1.}

Consider the case where switching after Stage 2 is not possible. In this case, the optimal choice of the number of observations, $n$, sampled from each population in Stage 1, on the Bayes risk associated with the selection in Stage 1 can be determined by maximizing the following expression with respect to $n$ :

$$
\begin{aligned}
E\left[w\left(\theta_{i^{*}}, s\right)\right] & =E_{X}\left[\max _{i=1, \ldots, k} E\left(\alpha \widehat{\theta}_{i}+\beta s_{i} \mid \mathbf{X}=\mathbf{x}\right)\right] \\
& =\alpha E\left[\mu_{[k]}(\mathbf{x})\right]+\beta[N-n(k-1)] \\
& =\alpha\left(\mu+\eta E\left[Z^{[k]}\right]\right)-n \beta(k-1)+\beta N \\
\text { where } \eta^{2} & =\frac{p}{v(p+v)}=\frac{n}{n v+\sigma^{2} v^{2}} \text { and } Z^{[k]} \sim \max _{i=1, \ldots, k} Z_{i} \text { where } Z_{i} \sim N(0,1)
\end{aligned}
$$

The last equality follows from a result in order statistics: essentially, we express the maximum of $\mu_{i}(\mathbf{X})$ in terms of its z-score, the maximum of standard normal distributions $Z_{i}$ (see Afonja, 
1972 and Dunnet, 1960). $\eta^{2}$ is the variance of the marginal distribution of $\mu_{i}(\mathbf{x}){ }^{42}$ Intuitively, $E\left[\mu_{[k]}(\mathbf{x})\right]$ represents the return to match quality while $[N-n(k-1)]$ represents the return from specific skills in choosing field $i^{*}$. Taking the derivative of the above expression with respect to $n$, setting it equal to zero, and simplifying yields the optimal number of observations, $n^{*}$, to be sampled in Stage 1:

$$
n^{*}\left(n^{*}+v \sigma^{2}\right)^{3}=v \sigma^{2}\left(\frac{\alpha \sigma E\left[Z^{[k]}\right]}{2 \beta(k-1)}\right)^{2}
$$

The unique positive root of the equation above represents the optimal number of observations, $n^{*} .{ }^{43}$ The optimal $n$ is clearly increasing in $\alpha / \beta$ and decreasing in $k$. In other words, a regime with late specialization, $n^{L}$, will yield higher wages than a regime with early specialization, $n^{E}$, if the return to match quality is sufficiently higher than the return to specific skills.

Proof of Corollary 1. We can express this directly as follows:

$$
E\left[w^{L}(\boldsymbol{\theta}, s)\right]>E\left[w^{E}(\boldsymbol{\theta}, s)\right] \Longleftrightarrow \frac{\alpha}{\beta}>\Omega=\frac{\left(n^{L}-n^{E}\right)(k-1)}{E\left[Z^{[k]}\right]\left(\eta^{L}-\eta^{E}\right)}>0
$$

where $\eta^{L}$ and $\eta^{E}$ are the $\eta$ for the regime with late and early specialization respectively. So a regime with late specialization is preferred if the returns to match quality are large relative to returns to specific skills.

Proof of Proposition 2. Consider the case where all switches are exogenous: i.e. some individuals are forced to switch without regard to the signals they receive in the Stage 2. In this case, the difference in expected wages between those individuals who switch and those who do not switch will simply be $E\left[w\left(\theta_{i^{*}}, s\right)\right]-E\left[w\left(\theta_{i^{a}}, s\right)\right]$. Following the derivation in the proof of proposition 1 , this expression can be shown to be strictly positive:

$$
\begin{aligned}
E\left[w\left(\theta_{i^{*}}, s\right)\right]-E\left[w\left(\theta_{i^{a}}, s\right)\right] & =\left\{\alpha E\left[\mu_{[k]}(\mathbf{x})\right]+\beta[N-n(k-1)]\right\}-\left\{\alpha E\left[\mu_{[k-1]}(\mathbf{x})\right]+\beta n\right\} \\
& =\alpha\left(\mu+\eta E\left[Z^{[k]}\right]\right)-\alpha\left(\mu+\eta E\left[Z^{[k-1]}\right]\right)+\beta(N-k n) \\
& =\alpha \eta E\left[Z^{[k]}-Z^{[k-1]}\right]+\beta(N-k n)>0 \\
\text { since } E\left[Z^{[k]}-Z^{[k-1]}\right] & >0 \text { where } Z^{[k]} \sim \max _{i} Z_{i}, Z^{[k-1]} \sim \max _{i \neq i^{*}} Z_{i} \text { and } Z_{i} \sim N(0,1)
\end{aligned}
$$

In the actual model, however, switching is endogenous. Consequently, expected wages have to be evaluated conditional on beliefs about the wages expected from switching and from not switching: $E\left[w\left(\theta_{i^{*}}, s\right) \mid w\left(\mu_{i^{*}}^{\prime \prime}, s\right)>w\left(\mu_{i^{a}}^{\prime}, s\right)\right]-E\left[w\left(\theta_{i^{a}}, s\right) \mid w\left(\mu_{i^{a}}^{\prime}, s\right)>w\left(\mu_{i^{*}}^{\prime \prime}, s\right)\right]$. These can be expressed

\footnotetext{
${ }^{42}$ In other words, $\eta^{2}=\operatorname{Var}(m(\mathbf{x}))$ where $m(\mathbf{x})=\int \mu_{i}(\mathbf{x} \mid \boldsymbol{\theta}) f(\boldsymbol{\theta}) d \boldsymbol{\theta}$. Wetherill and Ofosu determine $\eta^{2}$ in an analogous framework - see equation (9.5) on page 263.

${ }^{43}$ This equation is equivalent to equation (27) of Dunnett (1960). For the case of $k=2$, it is also equivalent to an equation derived by Bross (1950) since $E\left[\max \left(Z_{1}, Z_{2}\right)\right]=1 / \sqrt{\pi}$ (see Bose and Gupta, 1959).
} 
as follows:

$$
\begin{aligned}
& E\left[w\left(\theta_{i^{*}}, s\right) \mid w\left(\mu_{i^{*}}^{\prime \prime}, s\right)>w\left(\mu_{i^{a}}^{\prime}, s\right)\right]=\alpha E\left[\mu_{[k]}(\mathbf{x}) \mid \mu_{[k]}(\mathbf{x})>\underline{\lambda}\right]+\beta[N-n(k-1)] \\
& E\left[w\left(\theta_{i^{a}}, s\right) \mid w\left(\mu_{i^{a}}^{\prime}, s\right)>w\left(\mu_{i^{*}}^{\prime \prime}, s\right)\right]=\alpha E\left[\mu_{[k-1]}(\mathbf{x}) \mid \mu_{[k-1]}(\mathbf{x})<\bar{\lambda}\right]+\beta n \\
\underline{\lambda}= & \mu_{[k-1]}(\mathbf{x})-\left(\frac{q}{\pi(\pi+q)}\right)^{1 / 2} Y^{[k]}-\frac{\beta}{\alpha}(N-n k), \bar{\lambda}=\mu_{[k]}(\mathbf{x})+\left(\frac{q}{\pi(\pi+q)}\right)^{1 / 2} Y^{[k]}+\frac{\beta}{\alpha}(N-n k)
\end{aligned}
$$

Since these expressions are essentially the distributions associated with exogenous switching but truncated from above and below, it is clear that $E\left[w\left(\theta_{i^{*}}, s\right) \mid w\left(\mu_{i^{*}}^{\prime \prime}, s\right)>w\left(\mu_{i^{a}}^{\prime}, s\right)\right]>E\left[w\left(\theta_{i^{*}}, s\right)\right]$ and that $E\left[w\left(\theta_{i^{a}}, s\right) \mid w\left(\mu_{i^{a}}^{\prime}, s\right)>w\left(\mu_{i^{*}}^{\prime \prime}, s\right)\right]<E\left[w\left(\theta_{i^{a}}, s\right)\right]$. Hence, the difference remains positive in the case of endogenous switching.

Remarks on Proposition 3. In the case where switching after Stage 2 is possible, determining the optimal number of observations, $n$, sampled from each population in Stage 1 requires us to evaluate $E\left[w\left(\theta_{i^{* *}}, s\right)\right]$. Using the standard notation from earlier proofs, we can rewrite this expression in terms of the expectation of the maximum between the chosen field, $i^{*}$, and the second best-field, $i^{a}$ :

$$
\begin{aligned}
& E\left(\max \left[w\left(\mu_{i^{*}}^{\prime \prime}, s\right), w\left(\mu_{i^{a}}^{\prime}, s\right)\right]\right)=E_{X, Y}\left(\max \left[\alpha \frac{\pi \mu_{[k]}(\mathbf{X})+q Y^{[k]}}{\pi+q}+\beta s_{[k]}, \alpha \mu_{[k-1]}(\mathbf{X})+\beta s_{[k-1]}\right]\right) \\
& =E\left(\max \left[\alpha \mu_{[k]}(\mathbf{X})+\alpha \frac{q}{\pi+q}\left[Y-\mu_{[k]}(\mathbf{X})\right]+\beta[N-n(k-1)], \alpha \mu_{[k-1]}(\mathbf{X})+\beta n\right]\right) \\
& =\alpha E\left[\mu_{[k]}(X)\right]+\beta[N-n(k-1)]+E\left(\max \left[\frac{\alpha q}{\pi+q}\left[Y^{[k]}-\mu_{[k]}(\mathbf{X})\right], \Delta_{[k]}(\mathbf{X})\right]\right)
\end{aligned}
$$

where $\Delta_{[k]}(\mathbf{X})=\alpha\left(\mu_{[k-1]}(\mathbf{X})-\mu_{[k]}(\mathbf{X})\right)+\beta(n k-N)<0$

The first two terms represent the returns to match quality and specific skills as in the case where no switching is permitted. The impact of switching is captured by the final term which is non-negative in expectation since $Y$ is distributed with mean $\mu_{[k]}(\mathbf{X})$. Clearly, the possibility of switching can only serve to increase expected wages. Note that $\Delta_{[k]}(\mathbf{x})<0$ since switching will lead to a loss in specific skills $\beta(n k-N)<0$ and a loss in match quality $\mu_{[k-1]}(\mathbf{X})-\mu_{[k]}(\mathbf{X})<0$.

The effect of $n$ on expected wages when switching is possible depends on the derivative of the term $E\left(\max \left[\frac{\alpha q}{\pi+q}\left[Y^{[k]}-\mu_{[k]}(\mathbf{X})\right], \Delta_{[k]}(\mathbf{X})\right]\right)$ with respect to $n$. Unfortunately, it is not possible to evaluate it analytically. However, we can see that the term $\Psi$ will diminsh in importance when $\beta$ is large relative to $\alpha$. Intuitively, if the returns to specific skills are large, then we don't expect much switching to take place in any case. When $\alpha$ is large relative to $\beta$, the derivative of $\Delta_{[k]}(\mathbf{X})$ with respect to $n$ will be negative. Then $\Psi$ will be decreasing with $n$ and provide a countervailing weight to the first term $\alpha E\left[\mu_{[k]}(\mathbf{X})\right]$ which is increasing with $n$. Therefore, allowing for the possibility of switching implies that the highest benefit to switching will occur when $n$ is small. In other words, the possibility of switching is more valuable in a regime with early specialization than one with later specialization. Again, this is intuitive given that more mistakes are made with early specialization and it is therefore more valuable to be able to correct them through switching. The question remains whether $\Psi$ might be sufficiently decreasing in $n$ to overwhelm $\alpha E\left[\mu_{[k]}(\mathbf{x})\right]$ and lead a regime with early specialization to dominate the one with late specialization for all $\alpha / \beta$. Simulations suggest that this possibility is unlikely. 
Table 1: Summary Statistics for 1980 College Graduates

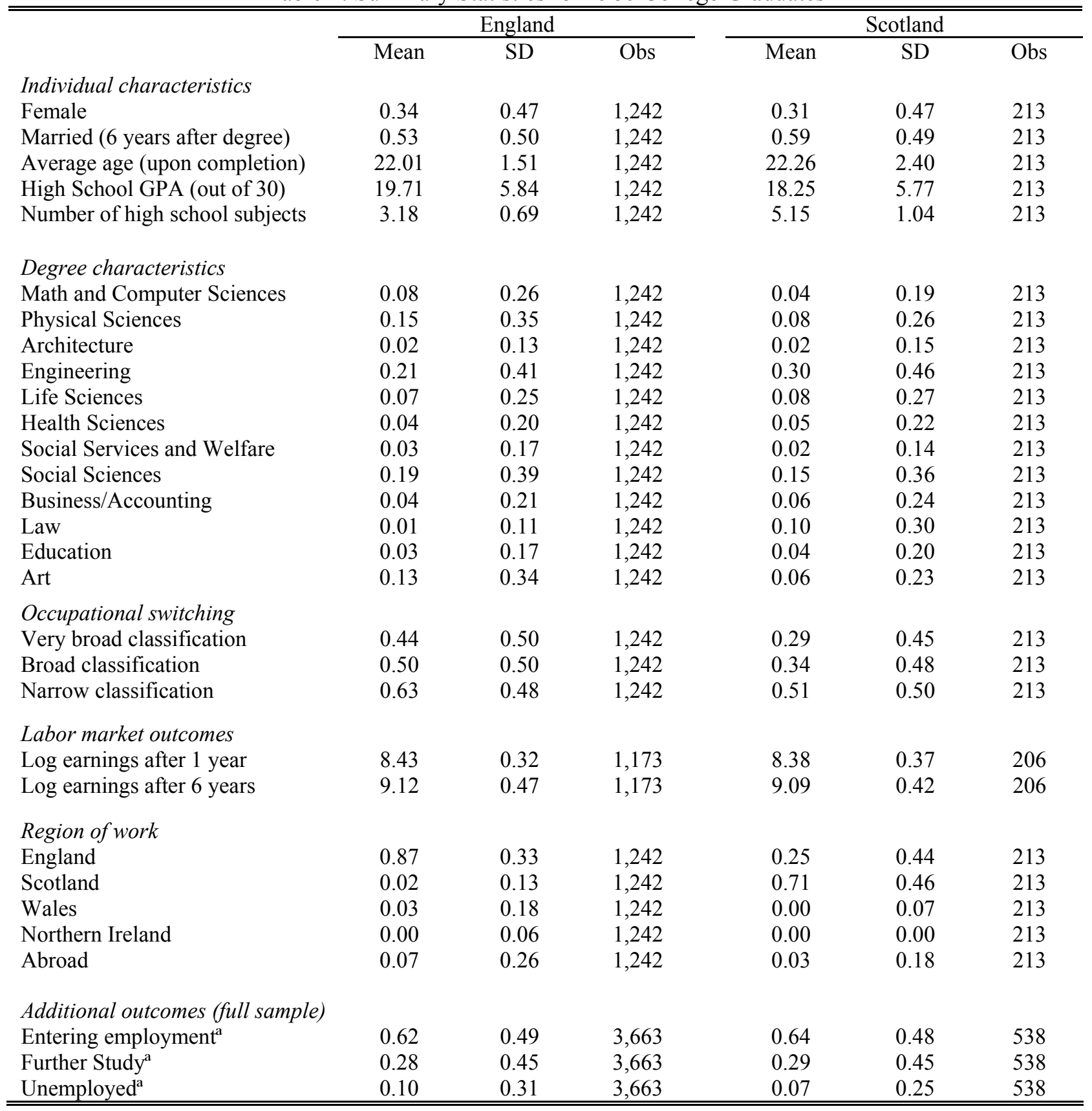

Notes: The base sample for the 1980 National Survey of Graduates and Diplomates (NSGD) includes all individuals who attained a BA degree in 1980 and were employed in a job during the 1st year following graduation and not pursuing graduate studies. Median age at the start of the degree is 19 for both nations. GPA is an average measure of the achievement in secondary school leaving exams out of 30 (but standardized by nation in all regressions). Honors is a measure of success at university standardized across nations taking descrete values from 0 (no honors) to 4 (highest honors). Occupational switch is defined as 1 if field of study at the undergraduate level is different from the occupational field of first job 6 months following degree and 0 otherwise (see Data Appendix for further discussion of classification groups). Log wages are both expressed in 1981 pounds after deflating using the consumer price index. Composition of fields of study and occupational fields are based on a broad classification (other classifications are discussed in the Data Appendix). Foreign students returning overseas are excluded from counts of Post-BA activity. ${ }^{a}$ is out of the unrestricted sample including unemployed and graduate students. 
Table 2: The Effect of Scottish Degree and Occupational Switching on Log Annual Earnings

dependent variable: log annual earnings

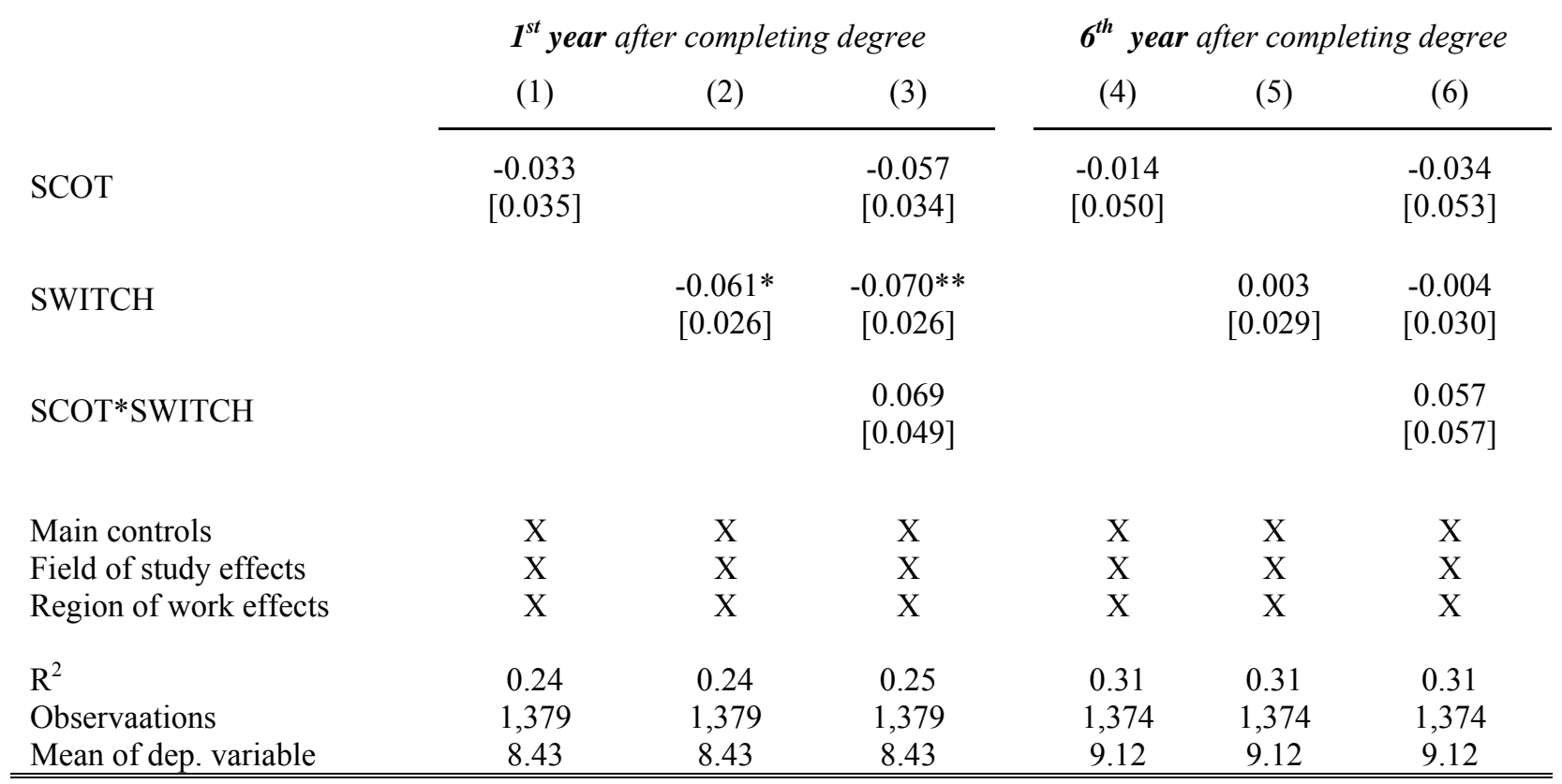

Notes: Huber-White standard errors in brackets. * and ** indicate significance at the $5 \%$ and $1 \%$ level respectively. Sample includes all students who aimed to attain a first degree in England and Scotland with occupation data and were not pursing further studies. Dependent variable in columns (1), (2), and (3) is defined as log annual earnings in the 1st year after completion of an undergraduate degree. Dependent variable in columns (4), (5), and (6) is defined as log annual earnings in the 6th year after completion of an undergraduate degree (deflated to 1981 pounds). SWITCH is defined as 1 if the broad field of study is different from the broad occupational field of first job in the 1st year following degree and 0 otherwise. SCOT is defined as 1 for Scottish high school exams and 0 for English high school exams. Main controls include sex, marital status, age, high school GPA, parent SES, and industry fixed effects. 
Table 3: The Effect of Scottish Degree and Occupational Switching over Time

dependent variable

\begin{abstract}
(epend variable
\end{abstract}
SCOT

SCOT

SWITCH

SCOT*SWITCH

Main controls

Field of study effects

Region of work effects

$\mathrm{R}^{2} \quad 0.1$

Observations

Mean of dep. variable growth in log annual earnings

(1)

(2)

0.034
$[0.058]$

[0.058]

1,379

0.69

(3)

0.039

[0.054]

$\begin{array}{ll}0.065 & 0.066\end{array}$

$[0.036] \quad[0.037]$

$-0.016$

[0.074]

$\begin{array}{ll}\mathrm{X} & \mathrm{X} \\ \mathrm{X} & \mathrm{X} \\ \mathrm{X} & \mathrm{X}\end{array}$

$\begin{array}{ll}X & X\end{array}$

X $\quad X$

X $\quad X$

0.19

1,379

0.69 occupational mobility

(4)

(5)

(6)

\begin{tabular}{ccc}
\hline & & \\
$-0.096^{*}$ & & $-0.137^{* *}$ \\
{$[0.048]$} & & {$[0.049]$} \\
& & \\
& $0.065^{*}$ & 0.052 \\
& {$[0.031]$} & {$[0.032]$} \\
& & \\
& & 0.108 \\
& & {$[0.065]$} \\
$\mathrm{X}$ & $\mathrm{X}$ & $\mathrm{X}$ \\
$\mathrm{X}$ & $\mathrm{X}$ & $\mathrm{X}$ \\
$\mathrm{X}$ & $\mathrm{X}$ & $\mathrm{X}$ \\
& & \\
0.08 & 0.08 & 0.08 \\
1,455 & 1,455 & 1,455 \\
0.24 & 0.24 & 0.24 \\
\hline
\end{tabular}

Notes: Huber-White standard errors in brackets. * and ** indicate significance at the $5 \%$ and $1 \%$ level respectively. Sample includes all students who aimed to attain a first degree in England and Scotland with occupation data and were not pursing further studies. Dependent variable in columns (1), (2), and (3) is defined as growth in log annual earnings in the 6 years following completion of the undergraduate degree. Dependent variable in columns (4), (5), and (6) is defined as 1 if occupational field after 6 years is different from the occupational field after 1 year following completion of an undergraduate degree. SWITCH is defined as 1 if broad field of study is different from the broad occupational field in the 1st year following degree and 0 otherwise. SCOT is defined as 1 for Scottish high school exams and 0 for English high school exams. Main controls include sex, marital status, age, high school GPA, parent SES, and industry fixed effects. 
Table 4: Effect of Scottish Degree on Occupational Switching for 1980 College Graduates

dependent variable: switched to occupation unrelated to field of study

\begin{tabular}{|c|c|c|c|c|c|c|}
\hline & \multicolumn{3}{|c|}{$1^{\text {st }}$ year after completing degree } & \multicolumn{3}{|c|}{$\boldsymbol{6}^{\text {th }}$ year after completing degree } \\
\hline & (1) & (2) & (3) & (4) & $(5)$ & (6) \\
\hline SCOT & $\begin{array}{c}-0.151^{* *} \\
{[0.035]}\end{array}$ & $\begin{array}{c}-0.086^{* *} \\
{[0.028]}\end{array}$ & $\begin{array}{c}0.014 \\
{[0.045]}\end{array}$ & $\begin{array}{c}-0.174 * * \\
{[0.036]}\end{array}$ & $\begin{array}{c}-0.110^{* *} \\
{[0.029]}\end{array}$ & $\begin{array}{c}-0.053 \\
{[0.046]}\end{array}$ \\
\hline Main controls & $\mathrm{X}$ & $\mathrm{X}$ & $\mathrm{X}$ & $\mathrm{X}$ & $\mathrm{X}$ & $\mathrm{X}$ \\
\hline Field of study effects & & $\mathrm{X}$ & $\mathrm{X}$ & & $\mathrm{X}$ & $X$ \\
\hline Region of work effects & & & $\mathrm{X}$ & & & $\mathrm{X}$ \\
\hline $\mathrm{R}^{2}$ & 0.03 & 0.35 & 0.36 & 0.03 & 0.30 & 0.31 \\
\hline Observations & 1,455 & 1,455 & 1,455 & 1,455 & 1,455 & 1,455 \\
\hline Mean of dep. variable & 0.48 & 0.48 & 0.48 & 0.52 & 0.52 & 0.52 \\
\hline
\end{tabular}

Notes: Huber-White standard errors, clustered by university in brackets. $*$ and $* *$ indicate significance at the $5 \%$ and $1 \%$ level respectively. Sample includes all students who aimed to attain a first degree in England and Scotland with occupation data and were not pursing further studies. Dependent variable is defined as 1 if field of study at the undergraduate level is different from the broad occupational field of the first job in the 1st year following the degree and 0 otherwise. SCOT is defined as 1 for having completed Scottish school leaving exams and 0 for English school leaving exams. Main controls include sex, marital status, age, high school GPA, and parent SES. 
Table 5: Subjective Assessments

dependent variable: "How beneficial has your qualification been to you in..."

"Getting an Interesting Job"

(1)

\begin{tabular}{cc}
\hline-0.154 & -0.202 \\
{$[0.126]$} & {$[0.128]$}
\end{tabular}

SWITCH

$-0.265 * *$

[0.075]

0.29

[0.189]

$\mathrm{X}$

Field of study effects

Observations

Mean of dep. variable
(2)

$-0.197 *$

[0.083]

0.315

[0.189]

$\mathrm{X}$

$\mathrm{X}$

1,345

3.24
"Becoming an Educated Person"

(3)

(4)

\begin{tabular}{cc}
\hline 0.041 & 0.044 \\
{$[0.112]$} & {$[0.116]$} \\
& \\
& \\
$0.312^{* *}$ & 0.082 \\
{$[0.066]$} & {$[0.078]$} \\
& \\
$-0.534^{* *}$ & $-0.536^{* *}$ \\
{$[0.177]$} & {$[0.178]$} \\
& $\mathrm{X}$ \\
$\mathrm{X}$ & $\mathrm{X}$ \\
& 1,345 \\
1,345 & 2.83 \\
2.83 & \\
\hline
\end{tabular}

Notes: Huber-White standard errors in brackets. * and ** indicate significance at the $5 \%$ and $1 \%$ level respectively. Sample includes all students who aimed to attain a first degree in England and Scotland with occupation data and were not pursing further studies. Results are from ordered probit regressions. Dependent variables are ordered categorical variables that take on values from 1 ("Not at all") to 4 ("A lot"). SWITCH is defined as 1 if broad field of study is different from the broad occupational field of first job in the 1st year following degree and 0 otherwise. SCOT is defined as 1 for Scottish high school exams and 0 for English high school exams. Main controls include sex, marital status, age, high school GPA, parent SES, industry fixed effects, log annual earnings in the first year and subjective measures of how beneficial the qualification has been to securing a good income. 
Appendix Table 1: Classification of Fields and Occupations

\begin{tabular}{|c|c|c|c|}
\hline Fields & S Subject codes (NSGD/USR-1980) & "Occupational Codes (NSGD) & "Occupational Codes (USR-1980) \\
\hline $\begin{array}{l}\text { 111 Math/Comp. Science } \\
1111 \text { Math Sciences } \\
1112 \text { Computer Sciences } \\
112 \text { Physical Sciences }\end{array}$ & $\begin{array}{l}\text { Mathematics (81) } \\
\text { Computer Science (82); Math/Comp. Science (31) }\end{array}$ & $\begin{array}{l}\text { Mathematician (444); Statistician }(242) \ldots \\
\text { Computer Programmer (244); Analyst/programmer (246)... }\end{array}$ & $\begin{array}{l}\text { Operational research (441); Statistician (452) } \\
\text { Systems analysis (442); Computer programming (443)... }\end{array}$ \\
\hline $\begin{array}{l}1121 \text { Chemistry } \\
1122 \text { Geology } \\
1123 \text { Physics }\end{array}$ & $\begin{array}{l}\text { Chemistry (34); Environmental Science (36) } \\
\text { Geology (35) } \\
\text { Physics (33); Mathematics/Physics (32) }\end{array}$ & $\begin{array}{l}\text { Chemical scientist (442) } \\
\text { Geological scientist (445) } \\
\text { Physical scientist (443) }\end{array}$ & $\begin{array}{l}\text { Scientist (510) + Chemical and allied industries (240-247) } \\
\text { Scientist (510) + Oil, mining industries (230-235) } \\
\text { Scientist (510) + Atomic energy (284); Other manufacturing }\end{array}$ \\
\hline $\begin{array}{l}121 \text { Architecture } \\
1210 \text { Architecture } \\
\text { 122 Engineering }\end{array}$ & Architecture (51); Town plan (52); Surveying (17) & Architect (511); Town planning (514); Draughtsman & Architect (551); Town planning (553); Surveying \\
\hline $\begin{array}{l}1221 \text { Mechanical } \\
1222 \text { Chemical } \\
1223 \text { Civil } \\
1224 \text { Electrical } \\
1225 \text { Industrial } \\
1226 \text { Materials } \\
1227 \text { Aeronautical }\end{array}$ & $\begin{array}{l}\text { Mechanical engineering (12) } \\
\text { Chemical Engineering (9) } \\
\text { Civil Engineering (10) } \\
\text { Electrical Engineering (11) } \\
\text { Production engineering (13) } \\
\text { Mining (14); Metallurgy (15) } \\
\text { Aeronautical engineer. (8) }\end{array}$ & $\begin{array}{l}\text { Mechanical or aeronautical engineer (461) } \\
\text { Chemical engineer ( } 481) \\
\text { Civil, municipal or structural engineer }(451) \ldots \\
\text { Electrical engineer (471); Electronic engineer }(472,473) \\
\text { Production engineer (482); Planning engineer }(483) \ldots \\
\text { Mining engineer (452); Metallurgist }(485) \\
\text { Mechanical or aeronautical engineer }(461)\end{array}$ & 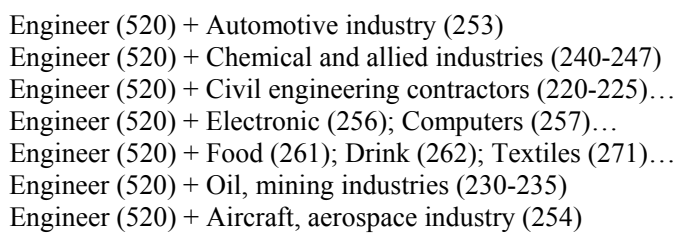 \\
\hline $\begin{array}{l}131 \text { Life Sciences } \\
1311 \text { Agriculture } \\
1312 \text { Biology }\end{array}$ & 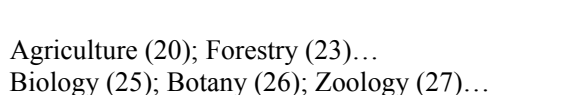 & $\begin{array}{l}\text { Farmer, farm manager, horticulturist ( } 600) \\
\text { Biological scientist, biochemist (441) }\end{array}$ & $\begin{array}{l}\text { Scientist (510) + Agriculture, horticulture, forestry }(210-214) \\
\text { Scientist }(510)+\text { Health authorities }(154)\end{array}$ \\
\hline $\begin{array}{l}132 \text { Health Sciences } \\
1321 \text { Physicians } \\
1322 \text { Dentists/Vets/Pharm } \\
1323 \text { Nursing/Related }\end{array}$ & $\begin{array}{l}\text { Medicine (3) } \\
\text { Dentistry (4); Veterinary (24); Pharmacology }(5,6) \\
\text { Studies allied to medicine/health (7) }\end{array}$ & $\begin{array}{l}\text { Medical practitioner (351) } \\
\text { Dentist (352); Veterinarian (382); Pharmacist (371)... } \\
\text { Nurse (360); Physiotherapist (374)... }\end{array}$ & $\begin{array}{l}\text { Medicine (631); Medical \& para-medical services (630) } \\
\text { Dentistry (632); Veterinary (640); Pharmacy (634)... } \\
\text { Nursing (633); Physio-occupational, speech \& therapy (636) }\end{array}$ \\
\hline $\begin{array}{l}2111 \text { Psychology } \\
2112 \text { Sociology/Social Work } \\
\text { 212 Social Sciences }\end{array}$ & $\begin{array}{l}\text { Psychology (46) } \\
\text { Sociology (47) }\end{array}$ & $\begin{array}{l}\text { Psychologist (324) } \\
\text { Sociologist (323); Welfare worker (333)... }\end{array}$ & $\begin{array}{l}\text { Psychology (623); Occupational guidance }(624) \\
\text { Social, welfare, religious (620); Social/welfare }(621) \ldots\end{array}$ \\
\hline $\begin{array}{l}2121 \text { Economics } \\
2122 \text { History/ Geography } \\
2123 \text { Govt., Public Admin. } \\
2124 \text { Other Social } \\
221 \text { Business }\end{array}$ & $\begin{array}{l}\text { Economics (41) } \\
\text { History (69); Archeology (70); Geography (42) } \\
\text { Government and public administration (44) } \\
\text { Social anthropology (48) }\end{array}$ & $\begin{array}{l}\text { Economist (241) } \\
\text { Librarian, information officer (294) } \\
\text { Inspector (263); General administration (local govt) (280)... } \\
\text { Social or behavioural scientist (325) }\end{array}$ & $\begin{array}{l}\text { Economic (450); Economist (451) } \\
\text { Librarian (721) Archivist (722) } \\
\text { Consumer protection, environmental health, safety }(653) \ldots \\
\text { Non-scientific research (730); Information research }(700) \ldots\end{array}$ \\
\hline $\begin{array}{l}2211 \text { Accounting, Finance } \\
2212 \text { Management } \\
2213 \text { Sales } \\
2214 \text { Related Business }\end{array}$ & $\begin{array}{l}\text { Accountancy }(43) \\
\text { Business, management studies }(40,53) \\
\text { Business, management studies }(40,53) \\
\text { Secretarial studies }(84)\end{array}$ & 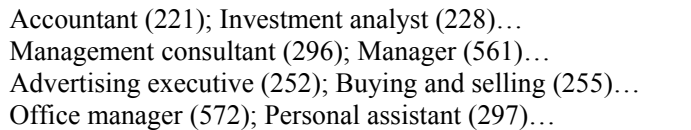 & $\begin{array}{l}\text { Financial (460); Accountancy (461); Banking }(462) \ldots \\
\text { Management \& supporting occupations }(400) \ldots \\
\text { Purchasing ( } 431) \text {; Selling (432); Marketing (434)... } \\
\text { Clerical, secreterial \& related (930)... }\end{array}$ \\
\hline $\begin{array}{l}222 \text { Law } \\
2220 \text { Law } \\
231 \text { Education }\end{array}$ & Law (45) & Judge (211); Advocate, barrister (212); Solicitor (213). & Baristor (471); Solicitor (472); Trusts (473).. \\
\hline $\begin{array}{l}2310 \text { Education } \\
232 \text { Arts }\end{array}$ & Education (1) & Teacher (secondary) (311); Teacher (primary) (312)... & Primary (611); Middle school (612); Secondary (613)... \\
\hline $\begin{array}{l}2321 \text { English/Languages } \\
2322 \text { Art } \\
2323 \text { Performing arts } \\
2324 \text { Religion/Philosophy }\end{array}$ & $\begin{array}{l}\text { English (55); French (57); German (59)... } \\
\text { Art (73) } \\
\text { Drama (74); Music (75) } \\
\text { Religion (72); Philosophy (71) }\end{array}$ & $\begin{array}{l}\text { Author, writer, journalist, editor (391) } \\
\text { Artist, commercial artist (401); Designer (402-406) } \\
\text { Actor, entertainer, musician, singer, stage manager (411)... } \\
\text { Clergy, minister of religion (340) }\end{array}$ & $\begin{array}{l}\text { Journalist (811); Technical writer ( } 711) \text {; Translater (712)... } \\
\text { Art, sculpture, design ( } 820) \text {; Fashion \& textiles ( } 823) \ldots \\
\text { Acting, music, sport (830); Broadcasting/stage/film (840)... } \\
\text { Pastoral (622) }\end{array}$ \\
\hline
\end{tabular}

Notes: Subject codes for USR are correct for 1972-1984 (different codes for 1985-1993) and occupational codes for the USR are correct from 1980-1993 (different codes for 19731979). Occupational codes omit some categories for brevity and indicated with "..." when excluded. Engineers and scientist in the USR are matched with industry codes in order to identify particular specializations within each category. Further details are available from the author. Broad fields are in bold. Very broad fields are expressed by the 2-digit codes. 
Appendix Table 2: Robustness Checks

\begin{tabular}{|c|c|c|c|c|}
\hline Coefficient of Interest & $\begin{array}{c}\text { Differential in } \\
\text { Wages (SCOT) } \\
(1) \\
\end{array}$ & $\begin{array}{c}\text { Wage Loss } \\
\text { (SWITCH) } \\
(2)\end{array}$ & $\begin{array}{c}\text { Differential in Wage } \\
\text { Loss }\left(\text { SCOT }{ }^{*} \text { SWITCH) }\right. \\
(3)\end{array}$ & $\begin{array}{c}\text { Differential in } \\
\text { Switching (SCOT) } \\
\text { (4) } \\
\end{array}$ \\
\hline Baseline & $\begin{array}{l}-0.057 \\
{[0.034]}\end{array}$ & $\begin{array}{c}-0.070 * * \\
{[0.026]}\end{array}$ & $\begin{array}{c}0.069 \\
{[0.049]}\end{array}$ & $\begin{array}{c}-0.086^{* *} \\
{[0.028]}\end{array}$ \\
\hline \multicolumn{5}{|l|}{ Classification of Fields } \\
\hline Narrow & $\begin{array}{l}-0.089^{*} \\
{[0.038]}\end{array}$ & $\begin{array}{c}-0.067 * * \\
{[0.021]}\end{array}$ & $\begin{array}{l}0.102 * \\
{[0.042]}\end{array}$ & $\begin{array}{l}-0.062 \\
{[0.034]}\end{array}$ \\
\hline Very Broad & $\begin{array}{l}-0.028 \\
{[0.039]}\end{array}$ & $\begin{array}{l}-0.071 * \\
{[0.029]}\end{array}$ & $\begin{array}{l}-0.023 \\
{[0.042]}\end{array}$ & $\begin{array}{l}-0.070^{*} \\
{[0.028]}\end{array}$ \\
\hline \multicolumn{5}{|l|}{ Occupational Restrictions } \\
\hline Unemployed as Switch & $\begin{array}{l}-0.057 \\
{[0.034]}\end{array}$ & $\begin{array}{c}-0.070^{* *} \\
{[0.027]}\end{array}$ & $\begin{array}{c}0.069 \\
{[0.049]}\end{array}$ & $\begin{array}{c}-0.089 * * \\
{[0.028]}\end{array}$ \\
\hline $\begin{array}{l}\text { Unclassified Occupations } \\
\text { as Switch }\end{array}$ & $\begin{array}{l}-0.054 \\
{[0.033]}\end{array}$ & $\begin{array}{c}-0.065^{* *} \\
{[0.022]}\end{array}$ & $\begin{array}{c}0.026 \\
{[0.044]}\end{array}$ & $\begin{array}{l}-0.064^{*} \\
{[0.026]}\end{array}$ \\
\hline $\begin{array}{l}\text { Include Graduate } \\
\text { Students }\end{array}$ & $\begin{array}{l}-0.055 \\
{[0.034]}\end{array}$ & $\begin{array}{c}-0.069^{* *} \\
{[0.026]}\end{array}$ & $\begin{array}{c}0.074 \\
{[0.049]}\end{array}$ & $\begin{array}{c}-0.088^{* *} \\
{[0.028]}\end{array}$ \\
\hline $\begin{array}{l}\text { Graduate Students as } \\
\text { Non-switch }\end{array}$ & $\begin{array}{l}-0.057 \\
{[0.034]}\end{array}$ & $\begin{array}{c}-0.070 * * \\
{[0.026]}\end{array}$ & $\begin{array}{c}0.069 \\
{[0.049]}\end{array}$ & $\begin{array}{c}-0.086^{* *} \\
{[0.028]}\end{array}$ \\
\hline \multicolumn{5}{|l|}{ Field Restrictions } \\
\hline Exclude Education & $\begin{array}{l}-0.062 \\
{[0.034]}\end{array}$ & $\begin{array}{c}-0.072 * * \\
{[0.027]}\end{array}$ & $\begin{array}{c}0.079 \\
{[0.050]}\end{array}$ & $\begin{array}{c}-0.092 * * \\
{[0.029]}\end{array}$ \\
\hline Education as Non-switch & $\begin{array}{l}-0.061 \\
{[0.034]}\end{array}$ & $\begin{array}{c}-0.071 * * \\
{[0.027]}\end{array}$ & $\begin{array}{c}0.079 \\
{[0.049]}\end{array}$ & $\begin{array}{c}-0.089 * * \\
{[0.028]}\end{array}$ \\
\hline Exclude Business & $\begin{array}{l}-0.055 \\
{[0.037]}\end{array}$ & $\begin{array}{c}-0.080^{* *} \\
{[0.027]}\end{array}$ & $\begin{array}{c}0.069 \\
{[0.050]}\end{array}$ & $\begin{array}{c}-0.079 * * \\
{[0.030]}\end{array}$ \\
\hline Business as Non-Switch & $\begin{array}{c}-0.058 \\
{[0.034]}\end{array}$ & $\begin{array}{c}-0.080 * * \\
{[0.027]}\end{array}$ & $\begin{array}{c}0.074 \\
{[0.049]}\end{array}$ & $\begin{array}{c}-0.074 * * \\
{[0.028]}\end{array}$ \\
\hline Exclude Combined fields & $\begin{array}{l}-0.026 \\
{[0.032]}\end{array}$ & $\begin{array}{l}-0.078^{*} \\
{[0.032]}\end{array}$ & $\begin{array}{c}0.062 \\
{[0.051]}\end{array}$ & $\begin{array}{c}-0.107 * * \\
{[0.028]}\end{array}$ \\
\hline \multicolumn{5}{|l|}{ Population restrictions } \\
\hline $\begin{array}{l}\text { Restrict to highest GPA } \\
\text { students }\end{array}$ & $\begin{array}{c}-0.138^{* *} \\
{[0.050]}\end{array}$ & $\begin{array}{l}-0.071 \\
{[0.040]}\end{array}$ & $\begin{array}{c}0.089 \\
{[0.106]}\end{array}$ & $\begin{array}{l}-0.081 \\
{[0.065]}\end{array}$ \\
\hline
\end{tabular}

Notes: Huber-White standard errors in brackets. ${ }^{*},{ }^{*}$, indicate significance at the $5 \%$ and $1 \%$ level respectively. Coefficients on all wage regressions (columns 1-3) include main controls, controls for field of study, region of work, and industry. Coefficients on occupational switching sample (column 4) include main controls, controls for field of study, but no controls for region of work. 
Figure 1: Expected Wages without Occupational Switching by Relative Return to Match Quality

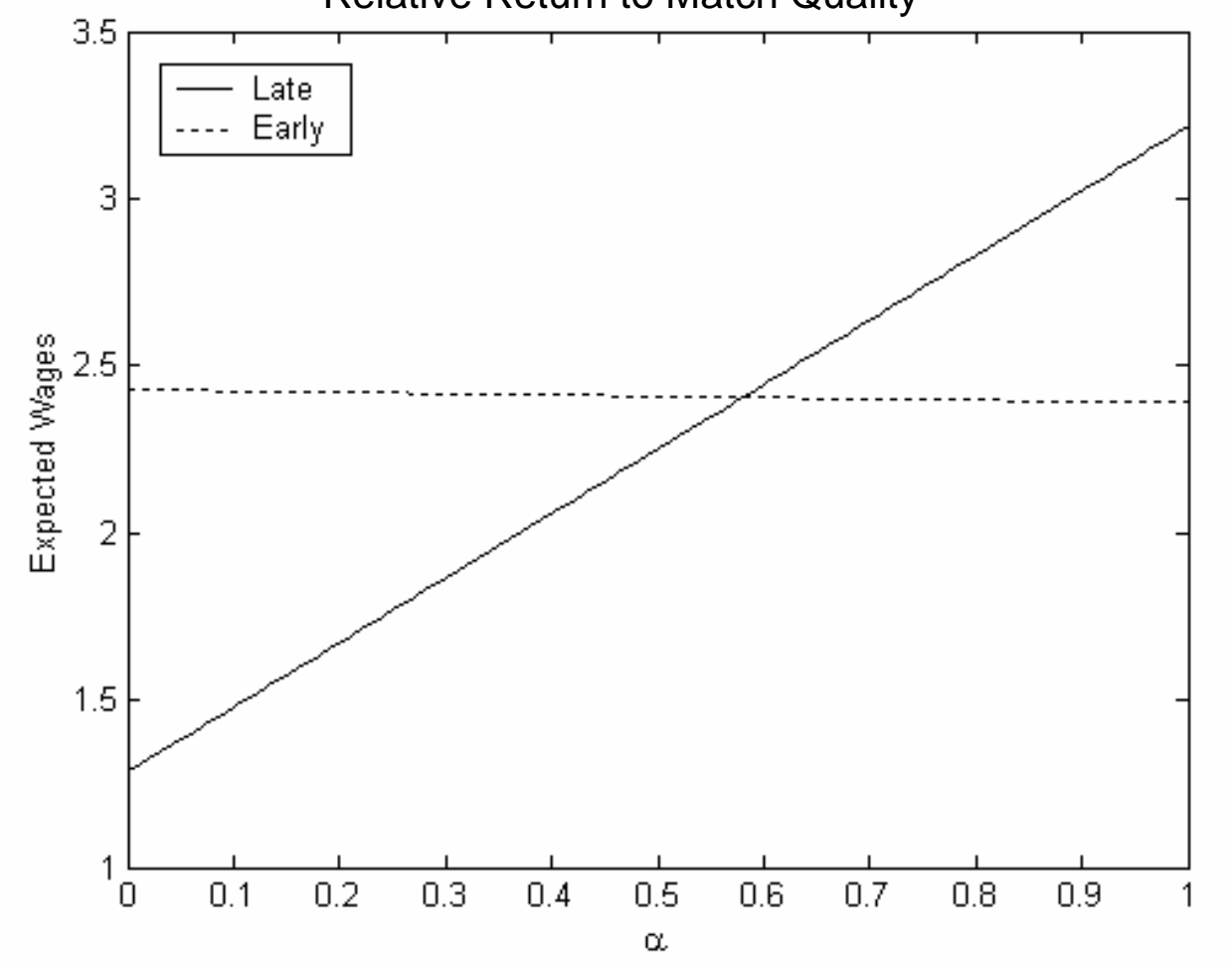

Figure 2: Expected Wages by Relative Return to Match Quality

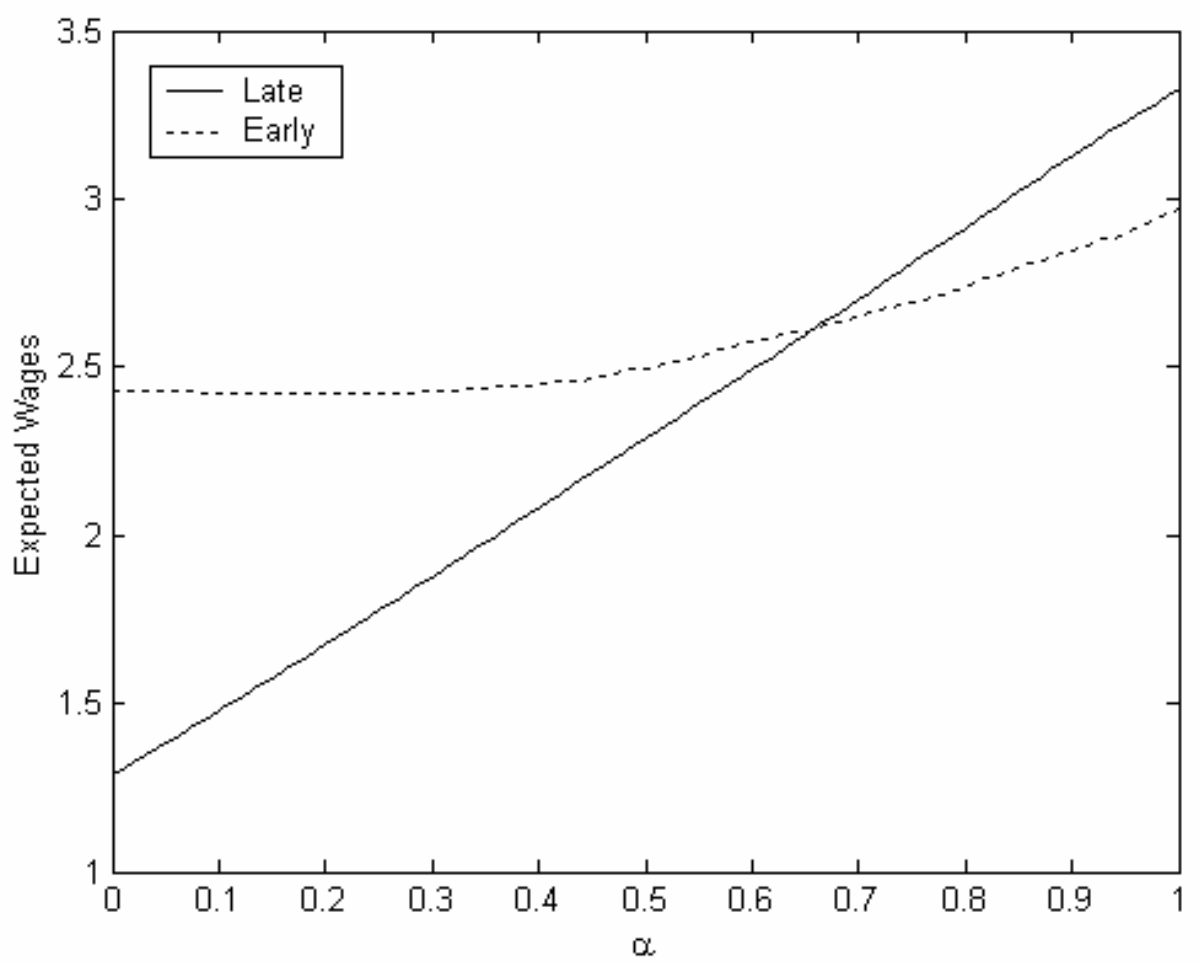

Notes: All simulations are based on 5000 repetitions for $\mathrm{k}=2, N=21, \mu=0, \sigma_{0}=25$, and $\sigma=100$. Early regimes are characterized by $n^{E}=2$; late regimes are characterized by $n^{L}=6$. The relative returns to match quality are normalized by taking $\beta=(1-\alpha)$ so that $(\alpha / \beta)$ goes from 0 to $\infty$ as $\alpha$ goes from 0 to 1 . Expected wages are log wages determined according to $E\left(\ln w_{j}\right)=E\left(\alpha \theta_{i}+\beta s_{i}\right)$ where $s_{j}=\left[s_{i} /(N / k)\right]+\mu$ are normalized skills. 
Figure 4: Predicted Log Wages in 1981 and 1986/87

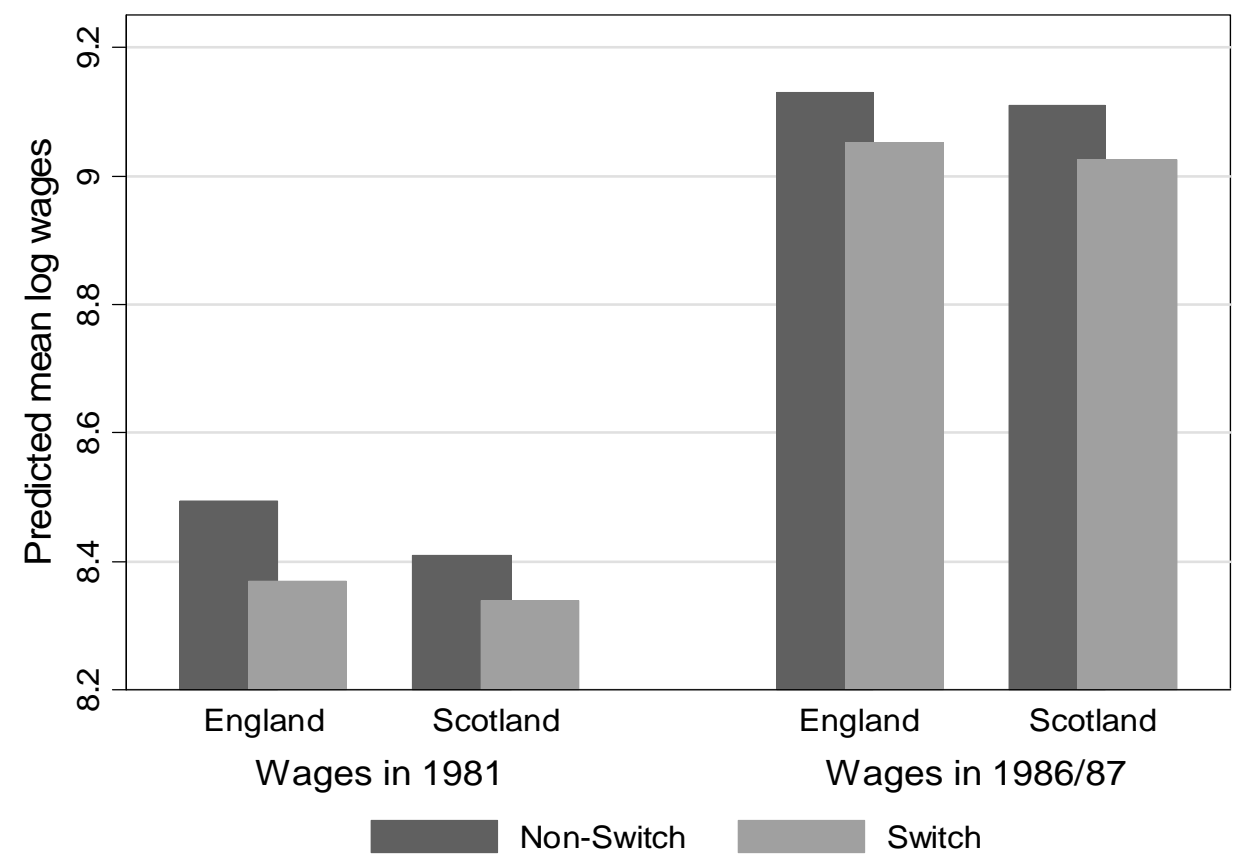

Notes: Mean log wages are predicted based on observable characteristics from the wage regressions of Table 2; specifically, columns (3) and (6). Log wages in 1986/87 are deflated to 1981 prices. 